\title{
Necrotising Enterocolitis \\ - epidemiology and imaging
}

\author{
Margareta Ahle
}

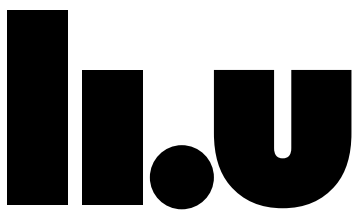

LINKÖPINGS UNIVERSITET

Department of Medical and Health sciences

Linköping University, Sweden

Linköping 2017 
(C) Margareta Ahle, 2017

ISBN 978-91-7685-455-6

ISSN $0345^{-0082}$

Printed in Sweden by LiU-Tryck, Linköping, Sweden, 2017 
To whoever may benefit from this work 



\section{Contents}

$\begin{array}{ll}\text { Abstract } & 7\end{array}$

List of papers 9

$\begin{array}{ll}\text { Author contributions } & 10\end{array}$

Abbreviations 11

$\begin{array}{ll}\text { Introduction } & 13\end{array}$

Background $\quad 15$

$\begin{array}{ll}\text { History } & 15\end{array}$

$\begin{array}{ll}\text { Pathophysiology } & 15\end{array}$

Clinical Presentation, Differential Diagnosis, $\quad 17$ and Classifications

* Imaging in differential diagnosis, stating, and 20 monitoring of NEC

Epidemiology - Incidence and Risk Factors $\quad 24$

* Incidence 24

* Seasonality and Clustering $\quad 24$

* Risk Factors 25

$\begin{array}{lr}\text { Prevention } & 29\end{array}$

Treatment $\quad 29$

* Indications for surgery 30

$\begin{array}{ll}\text { Outcome } & 31\end{array}$

Aims 33 
Epidemiological Studies, Papers I-IV 35

Case Ascertainment 35

* Subgroups According to Gestational Age and Birthweight 37

* Handling of Missing Data 37

* Incidence and Trends 37

* Seasonality and Clustering $\quad 38$

* Risk Factors 38

* Intestinal Failure 39

Survey on the Role of Imaging in the Management of NEC $\quad 40$

* Preparation of the Questionnaires 40

* Invitation of Respondents 40

* Distribution of Respondents 40

* Analysis of Proportions of Respondents 40

Results $\quad 43$

Incidence of Necrotising Enterocolitis (paper I and II) $\quad 43$

Risk Factors of Necrotising Enterocolitis (paper III) 43

Outcome (paper IV) 45

Missing Data $\quad 46$

The Role of Imaging in the Management of NEC 49

Discussion $\quad 51$

$\begin{array}{ll}\text { Conclusions } & 69\end{array}$

$\begin{array}{ll}\text { Sammanfattning på svenska } & 71\end{array}$

Acknowledgements $\quad 73$

References $\quad 75$

Original papers 


\section{Abstract}

Necrotising enterocolitis (NEC) is a potentially devastating intestinal inflammation of multifactorial aetiology in premature or otherwise vulnerable neonates. Because of the broad spectrum of presentations, diagnosis and timing of surgical intervention may be challenging, and imaging needs to be an integrated part of management.

The first four studies included in this thesis used routinely collected, nationwide register data to describe the incidence of NEC in Sweden 1987-2009, its variation with time, seasonality, space-time clustering, and associations with maternal, gestational, and perinatal factors, and the risk of intestinal failure in the aftermath of the disease.

Early infant survival increased dramatically during the study period. The incidence rate of NEC was 0.34 per 1,000 live births, rising from 0.26 per 1,000 live births in the first six years of the study period to 0.57 in the last five. The incidence rates in the lowest birth weights were 100-160 times those of the entire birth cohort. Seasonal variation was found, as well as space-time clustering in association with delivery hospitals but not with maternal residential municipalities.

Comparing NEC cases with matched controls, some factors positively associated with NEC were isoimmunisation, fetal distress, caesarean section, persistent ductus arteriosus, cardiac and gastrointestinal malformations, and chromosomal abnormalities. Negative associations included maternal preeclampsia, maternal urinary infection, and premature rupture of the membranes. Intestinal failure occurred in $6 \%$ of NEC cases and $0.4 \%$ of controls, with the highest incidence towards the end of the study period.

The last study investigated current practices and perceptions of imaging in the management of NEC, as reported by involved specialists. There was great consensus on most issues. Areas in need of further study seem mainly related to imaging routines, the use of ultrasound, and indications for surgery.

Developing alongside the progress of neonatal care, NEC is a complex, multifactorial disease, with shifting patterns of predisposing and precipitating causes, and potentially serious long-term complications. The findings of 
seasonal variation, space-time clustering, and negative associations with antenatal exposure to infectious agents, fit into the growing understanding of the central role of bacteria and immunological processes in normal maturation of the intestinal canal as well as in the pathogenesis of NEC. Imaging in the management of NEC may be developed through future studies combining multiple diagnostic parameters in relation to clinical outcome. 


\section{List of Papers}

This thesis is based on the following five papers, which are referred to by their Roman numerals (I - V)

I. Epidemiology and Trends of Necrotizing Enterocolitis in Sweden: 1987-2009

Ahle M, Drott P, Andersson RE. Pediatrics. 2013;132(2):e443-51

II. Population-based study showed that necrotising enterocolitis occurred in space-time clusters with a decreasing secular trend in Sweden. Magnusson A, Ahle M, Swolin-Eide D, Elfvin A, Andersson RE. Acta Paediatr Oslo Nor 1992. March 2017. doi:10.1111/apa.13851.

III. Maternal and Perinatal Risk Factors in Necrotizing Enterocolitis. Ahle M, Drott P, Elfvin A, Andersson RE.

Submitted for publication.

IV. Intestinal Failure after Necrotizing Enterocolitis - Incidence and Risk Factors in a Swedish Population-Based, Longitudinal Study Bexelius TS, Ahle M, Elfvin A, Björling O, Ludvigsson JF, Andersson RE.

V. The role of Imaging in Diagnosis and Management of Necrotizing Enterocolitis - A Multispecialist Survey and a Review of the Literature Ahle M, Ringertz H, Rubesova E.

Submitted for publication 


\section{Author Contributions}

\section{Paper I:}

I participated in the design of the study and the request of the data base extract, processed and analysed the data, participated in the interpretation of the results, wrote the first and the final manuscript, and managed the correspondence with the publishing journal.

\section{Paper II:}

I participated in the design of the study and the request of the data base extract, processed the data for analysis, and participated in the interpretation of results and in the editing of the manuscript.

\section{Paper III:}

I participated in the design of the study and the request of the data base extract, processed the data for analysis, participated in analysis and interpretation of the results, wrote the first and the final manuscript, and managed the manuscript submission.

\section{Paper IV:}

I participated in the design of the study and the request of the data base extract, processed the data for analysis, and participated in the interpretation of results and in the editing of the manuscript.

\section{Paper V:}

I participated in the design of the study, drafted the questionnaires, and managed their distribution, analysed the results, wrote the first and the final manuscript, and managed the manuscript submission. 


\section{Abbreviations}

ANID Acquired neonatal intestinal disease

AR Abdominal radiography

CDR Cause of death register (used in paper III and IV)

CI Confidence interval

CS Caesarean section

DAAS Duke abdominal assessment scale

GA Gestational age

HR Hazard ratio

ICD-9 International Classification of Disease, $9^{\text {th }}$ revision

ICD-10 International Classification of Diseases, $10^{\text {th }}$ revision

IF Intestinal failure

IRDS Infant respiratory distress syndrome

IRR Incidence rate ratio

IVH Intraventricular haemorrhage

MBR Swedish Medical Birth Register (used in paper III and IV)

NCD National Cause of Death Register (used in paper I)

NEC Necrotising enterocolitis

NPR National Patient Register

NIRS Near infra-red spectroscopy

OR Odds ratio

PDA Persistent ductus arteriosus

PE Pre-eclampsia

PI Pneumatosis intestinalis

PP Pneumoperitoneum

PROM Premature rupture of the membranes 
PVG Portal venous gas

ROP Retinopathy of the premature

SGA Small for gestational age

SIP Spontaneous intestinal perforation

SMB Swedish Medical Birth Register (used in paper I)

US Ultrasound

VLBW Very low birth weight 


\section{Introduction}

Necrotizing Enterocolitis (NEC) is a serious intestinal inflammation in neonates, which has developed alongside neonatal intensive care. The risk of NEC increases with increasing prematurity, but full-term infants may also be affected. A common pathophysiological pathway of multifactorial aetiology, rather than a uniform disease entity, NEC comes with a broad spectrum of clinical presentations - from the mild course of spontaneously resolving "medical" NEC to a fulminant course with rapid progression to massive bowel necrosis and death. Mortality is high in serious NEC and there is a substantial risk of long term complications, such as intestinal strictures, intestinal insufficiency, and neurodevelopmental impairment. Incidence rates, mortality rates, and identified or suspected risk factors have been observed to vary between populations and over time.

Ever since NEC was first described as a disease entity in the 1960's, imaging has played an important role in definition, staging, and monitoring of the disease. Available methods, however, often fail at confirming the diagnosis at an early stage and determining the need for surgical intervention in serious cases.

This thesis describes the incidence rates, timely variations, and risk factors of NEC in infants born in Sweden 1987-2009, the occurrence of intestinal failure in NEC cases and matched controls in this cohort, and the perceived role of imaging in the management of NEC as reported by neonatologists, paediatric surgeons, and paediatric radiologists from various parts of the world. 


\section{Background}

\section{History}

The first reports of what may, at least in some cases, have been NEC, appeared as early as the first half of the $19^{\text {th }}$ century. ${ }^{1-4}$ After more case reports during the $19^{\text {th }}$ and early $20^{\text {th }}$ centuries, it was named by in 1959 and described as a clinical, radiographic and pathologic entity during the sixties. ${ }^{3,5,6}$ In 1978, Bell et al defined a severity staging system for NEC to support therapeutic decisions, ${ }^{7}$ which is, after gentle modification, ${ }^{8}$ still in use. With the ninth edition of the International Classification of Diagnoses system (ICD9) in 1987 an ICD-code for Necrotizing Enterocolitis was specified.

The early NEC patients were weak and vulnerable neonates, most often preterm but usually at least 30 weeks of gestation. ${ }^{9}$ With continuously improving survival of the most premature, the patient population has changed, challenging researchers to revise their understanding of the disease over the course of time. ${ }^{1}$

During the last decade, advocates of so called NEC reductionism have emphasised the need to delimit NEC against other acquired neonatal intestinal diseases (ANIDs) and differentiate between NEC of different origin. ${ }^{9-12}$

\section{Pathophysiology}

The aetiology of NEC is multifactorial and may differ according to the degree of maturity of the patient. ${ }^{12}$ With few exceptions, the common prerequisites are, as stated by Sántulli et.al. in 1975, an injury to the intestine, the presence of bacteria, and availability of substrate for the bacteria, typically infant formula. 3,5 In general, this still holds true, although during the last 15-20 years, immunological processes at the intestinal mucosa and the role of "bacterial-host crosstalk" in maturation of a large variety of intestinal and immunological functions have been explored. Increasing knowledge about the complex interactions between the innate immunity system and colonising bacteria, proinflammatory factors and modifying systems, contributes to the understanding of how the susceptibility of the neonatal gut is influenced by variations in the composition of intestinal microbiota, together with the immaturity of intestinal functions, such as motility and digestion, structural and biochemical barrier functions, and circulatory regulation. ${ }^{13-18}$ The injury to the mucosa was initially 
thought to be ischemic in most cases, but in premature infants it is usually rather mediated by bacterial and inflammatory action,, 100 local ischemic changes being secondary to micro circulatory imbalance between vasoconstriction and vasodilatation as a result of inflammatory mediators, endothelial dysfunction and immature neurobiological regulation through the enteric and autonomous nervous systems. ${ }^{19}$ Intestinal injury and disruption of the neonatal gut barrier may, however, also be caused by splanchnic hypo-perfusion in response to a hypoxic or stressful event, ${ }^{20}$ which can explain the increased risk of NEC after such incidents in term and near-term infants, with greater intestinal maturity than preterm neonates. It has also been suggested that injury to the mucosa is caused by high concentrations of organic acids due to rapid fermentation of carbohydrates from stagnated milk substrate. ${ }^{10}$

Systemic effects of the local release of inflammatory mediators may further enhance the damage to the intestine, not only as a consequence of NEC but also as a contributing factor. ${ }^{21}$ The result is coagulation necrosis, acute and chronical inflammation, and bacterial overgrowth with gas formation in the lumen as well as in the intestinal wall. ${ }^{21}$

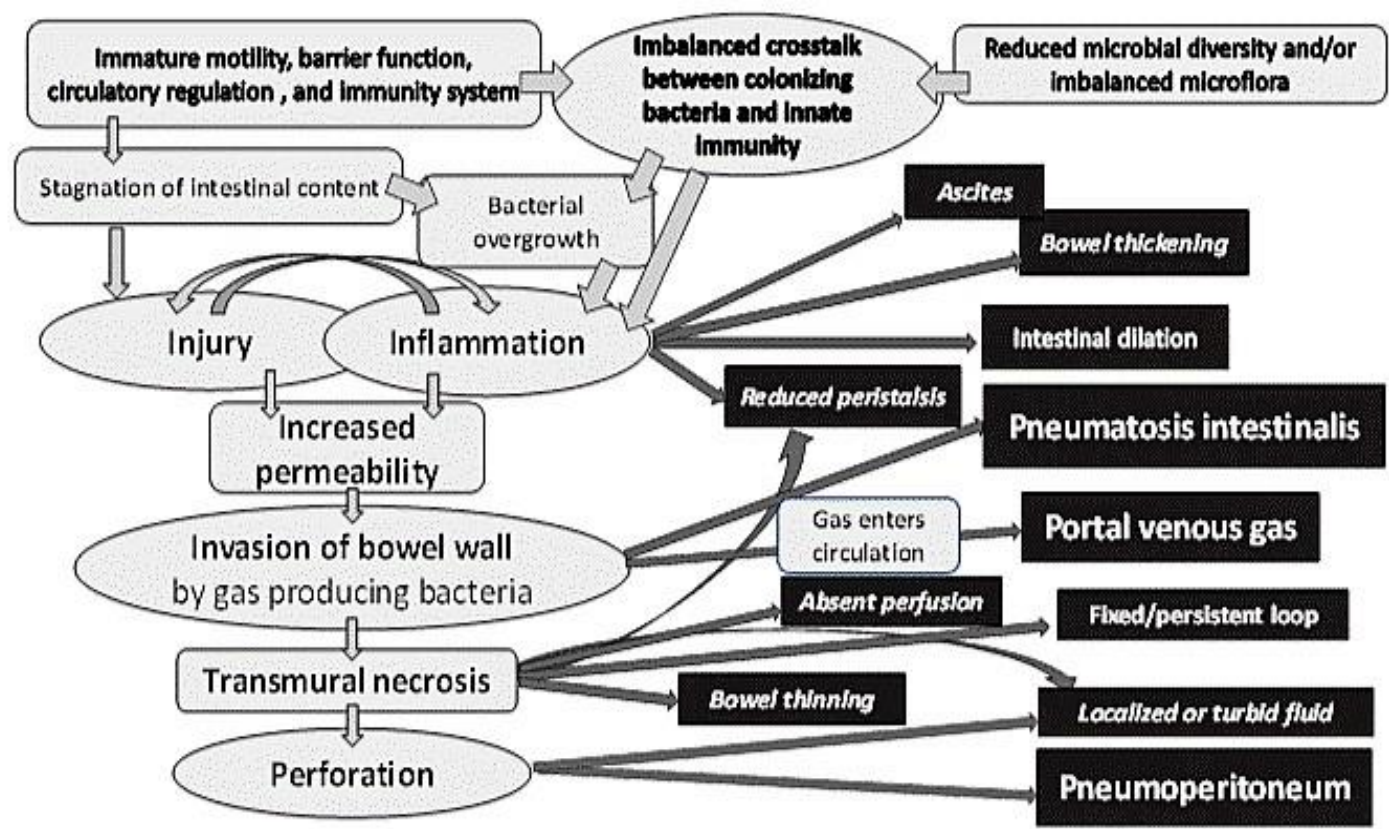

Figure 1: A simplified representation of the pathophysiology in NEC in relation to radiographic and ultrasonographic findings. 
Gas within the intestinal wall, referred to intramural gas or pneumatosis intestinalis (PI), is one of the hallmarks of NEC on abdominal radiographs (AR). The other hallmark is portal venous gas (PVG), assumed to arise from leakage of intramural gas into the mesenteric venous system, which drains into the portal vein, or even from entering of gas-producing bacteria into the circulation. ${ }^{22,23}$ Figure 1 depicts a simplified summary of the pathophysiology of NEC and its possible relations to radiographic and ultrasonographic findings.

\section{Clinical Presentation, Differential Diagnosis, and Classifications}

The clinical presentation of NEC ranges from mild and unspecific, resolving with discontinued feeding, parenteral nutrition, and antibiotics, to fulminant, with rapid progression to intestinal gangrene, sepsis, organ failure and death. Mild symptoms include temperature instability, bradycardia, apnea, desaturation, increasing gastric residuals and abdominal distension. More serious symptoms are signs of peritonitis, discoloration of the abdomen, and a palpable abdominal mass. In advanced disease there is hypotension and disseminated intravascular coagulation. ${ }^{2}$ Together with the picture on plain abdominal radiography these signs form the basis of Bell's criteria (Table 1).

\begin{tabular}{|c|c|c|c|}
\hline Stage & Clinical findings & Gastrointestinal findings & Radiographic findings \\
\hline 1 & Apnoea, bradycardia & $\begin{array}{l}\text { Gastric } \\
\text { Mild abdominal distension }\end{array}$ & Mild intestinal dilatation \\
\hline Ila & $\begin{array}{l}\text { Apnoea, } \\
\text { bradycardia } \\
\text { Mild inflammation }\end{array}$ & $\begin{array}{l}\text { Grossly bloody stools } \\
\text { Marked abdominal distension } \\
\text { Absent bowel sounds }\end{array}$ & $\begin{array}{l}\text { Marked intestinal dilatation } \\
\text { lleus }\end{array}$ \\
\hline IIb & $\begin{array}{l}\text { Thrombocytopenia } \\
\text { Mild acidosis } \\
\text { Inflammation }\end{array}$ & Abdominal tenderness & $\begin{array}{l}\text { Pneumatosis intestinalis } \\
\text { Portal venous gas }\end{array}$ \\
\hline IIla & $\begin{array}{l}\text { Moderate acidosis } \\
\text { Coagulopathy } \\
\text { Hypotension } \\
\text { Oliguria }\end{array}$ & Abdominal discolouration & $\begin{array}{l}\text { Pneumatosis intestinalis } \\
\text { Portal venous gas }\end{array}$ \\
\hline IIIb & Shock & Perforated bowel & Free abdominal air \\
\hline
\end{tabular}

Table 1: Bells Criteria as modified by Walsh and Kliegmann and adopted by Dördelmann et.al. ${ }^{24}$ 
The time of onset is typically around the second week in life but has been observed to correlate inversely with gestational age, 25,26 although there is great variation, presumably depending on variations in pathophysiological pathways. ${ }^{12,27}$ The early onset of term and near-term infants is thought to be due to an immediately precipitating perinatal event. ${ }^{10,11}$ A very early onset in an extremely premature infant may suggest Spontaneous Intestinal Perforation (SIP) rather than NEC. ${ }^{9}$ Onset during the second week in life is thought to correspond to the transition from the first to the second phase of intestinal colonisation. ${ }^{20}$ Time of onset has also been suggested to relate to the rate of advancement to full feedings. ${ }^{1}$

The clinical presentation itself may also be influenced by gestational age. The extremely premature frequently exhibit a less specific picture dominated by ileus, whereas hematochezia, abdominal tenderness and guarding are more commonly found in higher gestational ages. ${ }^{26}$ The difference may be explained by a more distal location with involvement of the colon in term infants.9,28,29 Extremely premature infants also seem less likely to present with PVG, possibly explained by lack of substrate in unfed or cautiously fed infants, reduced peristalsis in the immature gut, shortening of the phase of intramural bacterial growth in fulminant NEC, and lack of circulation in necrotic bowel..$^{23,24}$

Laboratory parameters include elevated C - reactive protein (CRP), ${ }_{16}$ neutropenia, leucocytosis, thrombocytopenia, hyponatraemia, acidosis and hyperglycaemia ${ }^{14}$, which may be present in various combinations. The acidosis is commonly of mixed metabolic type ${ }^{7}$, but respiratory acidosis may occur in advanced disease ${ }^{14}$.

It is generally accepted that NEC should be differentiated from SIP, which, although often misdiagnosed as perforated NEC, is recognized as an entity of its own.1,930,31 The possibilities to distinguish SIP from NEC without a laparotomy or autopsy are also being discussed and investigated. In a survey performed by Zani et.al. $46 \%$ of responding surgeons reported that they were able to diagnose SIP preoperatively. ${ }^{32}$ Blakely et.al. reported $95 \%$ correct preoperative diagnosis in 156 infants operated on for NEC or SIP, 33 and Bohnhorst et.al. found good sensitivity and specificity, using ultrasound in combination with Gordon's classification (see below). ${ }^{34}$ In contrast, Allin et.al. 
suggested that the conditions be treated equally preoperatively and differentiated postoperatively according to the intraoperative finding. ${ }^{35}$

Apart from SIP, suggested differential diagnoses include viral enteritis of infancy, feeding intolerance of prematurity, cow's milk protein allergy, ischemic bowel disease due to cardiac anomalies, and Hirschsprung's disease. ${ }^{9,11,36}$ Aspects aiding in differential diagnosis would be the gestational age, age at onset and feeding volumes, stool cultures, blood cultures, the presence or absence of coagulopathy, C-reactive protein levels, white blood cell and platelet counts and clinical symptoms such as hematochezia and ileus. ${ }^{9,36}$ In 2007, Gordon and coworkers suggested a classification, or system for differential diagnosis, which seeks to take all these aspects into account. ${ }^{4}$ Suggestions for subdivision of NEC of different origin have followed. ${ }^{12}$

\begin{tabular}{lllll} 
Signs and symptoms & FIP & NEC & SIP & VEI \\
\hline \hline Age at onset & $<2$ weeks & $>2$ weeks & $<2$ weeks & $>2$ weeks \\
Feeds $(\mathrm{ml} / \mathrm{kg} / \mathrm{d}$ ) & $<80$ & $>80$ & $<40$ & $>120$ \\
Pneumatosis & no & yes & no & common \\
Free abdominal air & no & $20-30 \%$ & $100 \%$ & $30-40 \%$ \\
lleus & no & yes & variable & not initially \\
Bloody stools & no & uncommon & no & yes \\
Coagulopathy & no & if severe & no & if severe \\
Pathogens & none & enterobacteria & none & rotavirus; \\
& & & & enterovirus \\
Clustering & no & no & no & yes \\
Surgical finding & none & pneumatosis & focal perforation & pneumatosis \\
& & mural necrosis & & ascites \\
& & & & bowel necrosis \\
Histological finding & none & mucosal obliteration & robust mucosa & mucosal obliteration \\
& & necrosis & focal necrosis & necrosis \\
& & inflammation & less inflammation & inflammation \\
\hline \hline
\end{tabular}

Table 2: Gordon's classification, adopted from a summarised version by Bohnhorst et.al. ${ }^{34}$ FIP: feeding intolerance of prematurity, NEC: necrotizing enterocolitis, SIP: spontaneous intestinal perforation, VEl: viral enteritis. Gordon et.al. ${ }^{9}$ further divides NEC into preterm NEC in BW $<1250 \mathrm{~g}$ and ischemic NEC in $>1250 \mathrm{~g}$ and includes cow's milk protein allergy as a differential diagnosis in BW $>1250$ g.

Battersby et.al. recently reported on an attempt to create a propensity score for NEC, based on the sensitivity and specificity of a carefully selected combination of clinical and radiographical signs together with the probability of NEC at different gestational ages. Findings at laparotomy or autopsy, or a reasonably certain clinical diagnosis of NEC, were used as reference standard. 
The signs or combination of signs were assigned 1-3 points each as follows (points within brackets): Abdominal discoloration (1), Abdominal tenderness (1), the combination of increased or bilious aspirates and abdominal distention (1), one or more of pneumoperitoneum, portal venous gas, and fixed loop on AR (1), blood in stool (2) pneumatosis intestinalis on AR (3). Accepting a positive predictive value of $60 \%$ or more, the resulting cut-off scores for a diagnosis of NEC were set to 2 in gestational ages $<30$ full weeks, 3 in gestational ages 30-36 full weeks, and 4 in gestational ages $\geq 37$ weeks.

\section{Imaging in Differential Diagnosis, Staging and Monitoring of NEC}

Ever since NEC was described as a clinical, pathologic, and radiographic entity, imaging has been an integrated part of its management. It was soon recognized, that subtle radiographic signs of early NEC may appear before clinical signs of the disease and progress ahead of clinical deterioration, but also that the typical radiographic signs, pneumatosis intestinalis (PI) and portal venous gas (PVG), were often transient, pneumoperitoneum (PP) frequently missing in spite of intestinal perforation, and the overall sensitivity of AR low, especially in extremely low birth weight infants. $22,26,31,34,37-43$ These insights, together with the reports of early detection of PVG with ultrasound by Merritt et.al. ${ }^{44}$ and the studies of mesenteric circulation in neonates by van Bel et.al, ${ }^{45}$ led Fotter and Sorantin to suggested a standardized algorithm for early diagnosis and evaluation of progress, in which AR in two projections and ultrasonography was recommended for diagnosis in all cases, followed by repeated examinations at 4-6 hours interval, or at least daily, with supine and left lateral decubitus films each time, and repeated ultrasounds at every 12 to 24 hours. ${ }^{46}$

Apart from low sensitivity, AR also suffers from of considerable intra- and interobserver variability ${ }^{43,47,48}$ and presumably some variability in the quality of the radiographs, depending on the skill of the radiographer. To improve diagnostic accuracy, radiographic patterns have been analysed at greater detail, defining early signs, such as ileus and elongation of bowel loops, loss of bowel wall definition, and a disorganised, atonic pattern of intestinal gas. ${ }^{41}$ These early signs, together with the more typical findings of pneumatosis intestinalis, portal venous gas, and pneumoperitoneum, have been organised into the Duke Abdominal Assessment Scale (DAAS), a standardised 10 point radiographic 
scale, increasing with disease severity and likelihood of surgical intervention. ${ }^{49}$ and reported to have fair interobserver agreement. ${ }^{50,51}$

Table 3: The DAAS scale ${ }^{49}$

\begin{tabular}{ll}
\hline \hline 0 & Normal gas pattern \\
1 & Mild distention \\
2 & Moderate distention or normal with bubbly lucencies that are likely stool \\
3 & Focal moderate distention of bowel loops \\
4 & Separation or focal thickening of bowel loops \\
5 & Featureless or multiple separated bowel loops \\
6 & Possible pneumatosis with other abnormal findings \\
7 & Fixed or persistent dilation of bowel loops \\
8 & Pneumatosis (highly probable or definite) \\
9 & Portal venous gas \\
10 & Pneumoperitoneum
\end{tabular}

In addition to this effort to reduce interobserver variability and communication uncertainty through systematic reading and reporting of AR findings ${ }^{50}$ efforts to improve diagnostic accuracy include development and evaluation of the use of ultrasound (US) in NEC. ${ }^{52,53}$

In the 1980's and 90's PVG on US was described as an early sign of NEC, $44,54,55$ as opposed to on AR, where it is considered a sign of advanced disease. ${ }^{23,56-59}$ Later studies, however, have not always been able to confirm the high sensitivity. ${ }^{24,60,61}$ The specificity of most sonographic findings, i.e. PVG, bowel wall thinning, PI, echoic free fluid and focal fluid collections, on the other hand, has been found to be high. ${ }^{24,61}$ In respect to NEC reductionism, the combination of PVG and PI on ultrasound was highly sensitive and specific for NEC in relation other SIP, when retrospectively evaluated with surgical results as reference standard. ${ }^{34}$

Several studies of flow velocities in the superior mesenteric artery in connection with NEC were reported in the early 1990's, however with inconsistent results. ${ }^{62-67}$

Complex ascites (focal or echoic fluid) has been associated with intestinal gangrene, perforation, the need for surgery, or otherwise poor outcome. $39,42,68,69$ PP detected with US may also predict poor outcome, as well as a combination of three or more of: increased wall echogenicity, absent perfusion, PVG, bowel wall thinning, bowel wall thickening, free fluid with echoes or PI. ${ }^{39}$ Absent perfusion detected with doppler, in combination with various other signs, has been associated with bowel necrosis ${ }^{70,71}$ and the finding of a dilated, elongated 
intestinal loop on $\mathrm{AR}^{72}$ which has in turn been associated with poor outcome. ${ }^{53}$

An overview of ultrasonographic and radiographic signs and their occurrence in the literature is given in tables 4 and 5 . The selection of articles may, however, not be complete.

Table 4:

Reports on radiographic signs of NEC in the literature

Rabinowitz ${ }^{37}$

Siegle 40

Daneman $^{22}$

Kogutt ${ }^{41}$

Mata ${ }^{48}$

Leonard $^{73}$

${ }^{*}$ Cikrit $^{74}$

Frey $^{75}$

*Kennedy ${ }^{76}$

Kosloske ${ }^{56}$

Brill ${ }^{77}$

Bömelburg ${ }^{78}$

Rehan $^{43}$

Molik $^{57}$

$\mathrm{Tam}^{31}$

Faingold ${ }^{70}$

$\mathrm{Kim}^{60}$

Sharma ${ }^{23}$

Coursey $^{50}$

Dördelman ${ }^{24}$

Bonhorst $^{34}$

Dilli61

Muchantef ${ }^{53}$

Silva ${ }^{72}$

Muller $^{79}$

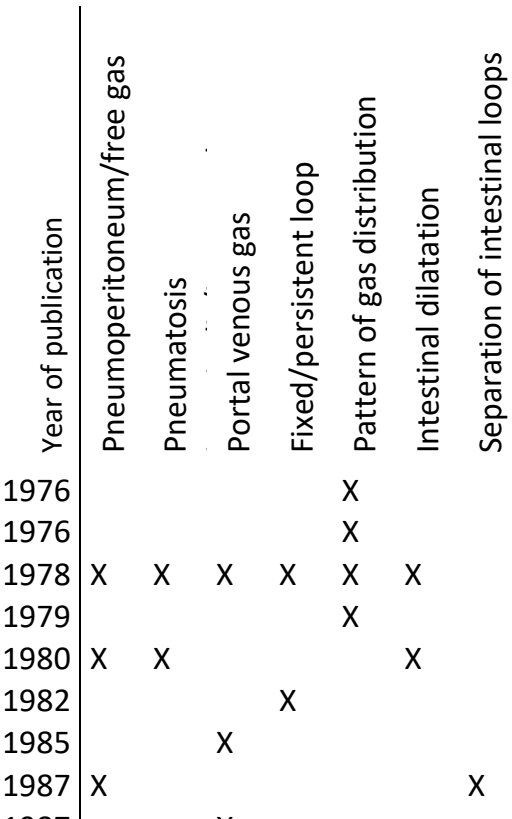

$1987 \times \quad X$

$1988 \times \quad X \quad X$

$1990 \mathrm{X}$

$1992 \quad X \quad X \quad x \quad X$

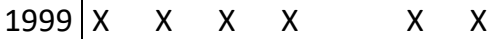

$2001 \quad x$

$2002 \times x \quad x$

$2005 x$

2005

$2005 \quad x \quad x \quad x$

$\begin{array}{llllllll}2009 & X & X & X & X & X & X & X\end{array}$

$2009 x$

2011

2011 X $\quad x \quad x \quad x \quad x$

2013 X $\quad X \quad X \quad X \quad x \quad x$

$2013 \quad X \quad X \quad X \quad X$

* Abstracts only accessed

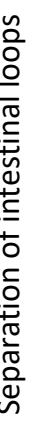

$x$

$\mathrm{x}$ 
Table 5:

Reports on ultrasonographic signs of NEC in the literature

\section{Merritt $^{44}$}

Lindley $^{80}$

Bömelburg ${ }^{78}$

Coombs $^{62}$

Kempley $^{63}$

Deeg ${ }^{64}$

Miller ${ }^{69}$

Riccabona ${ }^{65}$

Schmidt ${ }^{66}$

Faingold ${ }^{70}$

$\mathrm{Kim}^{60}$

Silva ${ }^{72}$

Dördelmann ${ }^{24}$

McBride $^{42}$

Bohnhorst ${ }^{34}$

Dilli ${ }^{61}$

Muchantef ${ }^{53}$

Silva ${ }^{72}$

Yikilmaz ${ }^{71}$

Palleri ${ }^{68}$

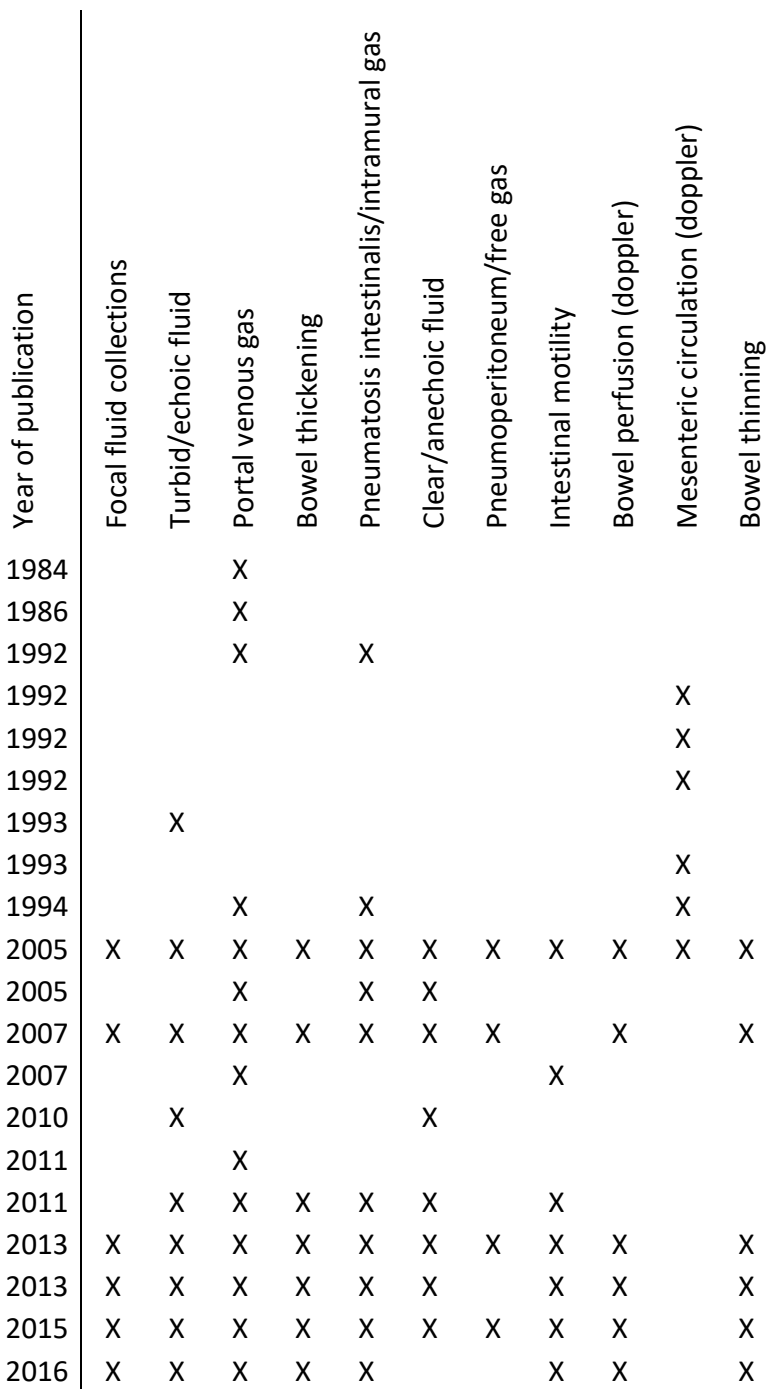

US has been suggested to be used for: detection of PI, PVG, and intra-abdominal fluid and evaluation of bowel peristalsis, thickness, and perfusion of the bowel wall in neonates with mild symptoms and nonspecific plain film findings; confirmation of an indication for surgery in neonates with more advanced NEC; additional information in neonates with a paucity of bowel gas or a fixed bowel loop over serial radiographs; and demonstration of PVG in patients with diffusely gas distended bowel, where evaluation of the abdominal cavity is impaired by intraluminal gas. $.52,53$ 


\section{Epidemiology - Incidence and Risk Factors}

* Incidence

NEC incidence is known to vary geographically with frequencies thought to be especially low in Japan, Switzerland, and some Scandinavian countries.5,81,82 Incidence rates from the United States vary between 0.7 and 1 in 1000 live births, with significantly higher incidence rates in infants of African American descent (1.6-2.2 per 1000 live births) than whites (0.5-0.6 per 1000 live births). ${ }^{25,83-85} \mathrm{In}$ the United Kingdom and Ireland, 0.3 cases of proven NEC in 1000 live births were estimated during 1981-1984 (0.5 when including suspected cases). ${ }^{28}$

Among infants with birth weights of $1500 \mathrm{~g}$ or less, incidence rates of 2-7\% have been reported in various studies from Europe, North America, and South Korea at different times between 1983 and 2014. ${ }^{86-89}$ A Canadian multicentre study reported $5.1 \%$ in 16,669 neonates of $<33$ weeks gestational age 2003-2008 with considerable variation between participating units. ${ }^{27}$ In the national extremely preterm infants study in Sweden (EXPRESS) $6 \%$ of the live born with a gestational age of less than 27 full weeks developed NEC. ${ }^{90}$ In England, Rees et.al. found $14 \% \mathrm{NEC}$ of all stages in birthweights $<1,000 \mathrm{~g}$ and gestational ages $<26 \mathrm{w}$ in 2005-2006, and Battersby et.al. found severe NEC, i.e. requiring surgery, or stated as the primary cause of death, in $3 \%$ of infants with gestational ages $<32$ weeks 2012-1013. The proportion of term infants varies between $7 \%$ and $25 \% .^{25,28,92-97}$

Advances in ante- and perinatal care of premature infants have resulted in dramatically improving early survival in this group, which may lead to increasing incidence of NEC and other diseases typical to the premature. $25,83,98,99$

Seasonality and clustering

NEC has been reported sometimes to occur in clusters or epidemics, ${ }^{100-104}$ especially in winter- and early summer months, and seasonal variation has been described. ${ }^{105,106}$ According to some authors, the incidence of viral induced NEC is increasing. ${ }^{30}$ No specific pathogen has been identified as causative of NEC, but a great number of microbial organisms, have occasionally been isolated in conjunction with outbreaks, 5,10,107-109 and infection control measures have been effective in preventing further cases. ${ }^{102,108,110}$ 
Risk factors

It is well known that pre-term birth is the most consistent predisposing factor for NEC. Beeby and Jeffrey concluded: "In the 25-29 week range all babies are at risk on the basis of extreme prematurity. In the 30-36-week range, asphyxiated and growth retarded babies are at increased risk, while at term a major predisposing event appears to be required." 97 Palmer et al showed that risk factors varied according to birth weight. ${ }^{111}$

In some studies of the full-term sub-group, all NEC cases were admitted to an NICU for a reason other than NEC, 112,113 whereas others report that such a predisposing factor seemed to be absent in $12.5 \%-60 \% .{ }^{96,114,115}$ Identified risk factors for NEC, apart from prematurity and low birth weight, vary between studies with sometimes contradictory results. There is support for familial predisposition, ${ }^{116}$ and genetic factors may influence several of the pathogenetic pathways of NEC. ${ }^{117}$

Table 6 presents a selection of factors, which have at some stage been suspected to predispose for NEC. Some of them are commented on below.

Pre-eclampsia (PE) in the mother has been thought of as a potential risk factor of NEC through reduced placental perfusion, ischemia, and fetal growth restriction. ${ }^{118}$ In a study of 211 low birth weight infants in 1995-1998, PE was identified as an independent risk factor for NEC. ${ }^{119}$ A larger prospective study reached the same conclusion, but statistical significance was not confirmed in multivariable regression. ${ }^{118}$ Results of retrospective studies include an independent association of PE with NEC in the subgroup of growth restricted neonates only, ${ }^{120}$ overrepresentation of PE among NEC cases without statistical significance, ${ }^{121}$ or PE as a significant risk factor for NEC but tested in univariable analyses only. ${ }^{122}$

Antibiotics administered to the mother: In a Malaysian register study, intrapartum antibiotics administered to mothers were found to be protective of NEC. ${ }^{123}$ A meta-analysis from 2013 of treatment of mothers for premature rupture of membranes, however, found a tendency towards lower risk for NEC with a shorter course of antibiotics, but, except for the combination of amoxicillin and clavulanic acid, antibiotics per se did not increase the risk. ${ }^{124}$ 
Table 6: Some suggested risk factors for NEC

\begin{tabular}{|c|c|}
\hline Increasing maternal age $\mathrm{e}^{123}$ & Congenital cardiovascular \\
\hline Low maternal age ${ }^{125}$ & abnormality $82,87,93,106,112,114,115,138,144,145$ \\
\hline Maternal cigarette smoking ${ }^{126}$ & PDA/treatment for PDA $82,85,86,146,147$ \\
\hline Maternal substance abuse ${ }^{127}$ & Hyaline membrane disease/IRDS/respiratory \\
\hline Maternal HIV infection ${ }^{128,129}$ & problems ${ }^{27,92,111,114,136,148}$ \\
\hline Pre-eclampsia ${ }^{118-120,122}$ & Congenital pneumonia ${ }^{123}$ \\
\hline Intrahepatic cholestasis of pregnancy $y^{106}$ & $\begin{array}{l}\text { Assisted ventilation/prolonged ventilator } \\
\text { support/CPAP } 28,82,111,139\end{array}$ \\
\hline Antenatal Indomethacin ${ }^{130}$ & Treatment with narcotics $27,82,136$ \\
\hline Chorioamnionitis ${ }^{114,131-135}$ & Acidosis/treatment for acidocis/lower cord \\
\hline Prolonged rupture of membranes ${ }^{114}$ & $\mathrm{pH}^{82,97,138}$ \\
\hline Placental abruption ${ }^{94,136}$ & Hypotension/chock/treatment for \\
\hline Antenatal doppler abnormalities ${ }^{129,137,138}$ & hypotension $^{82,94,147,149}$ \\
\hline Multiple birth ${ }^{82,129}$ & Early onset bacterial sepsis ${ }^{88,112,147}$ \\
\hline Birth outside a perinatal centre ${ }^{27,82}$ & Hypoglycemia ${ }^{114,148}$ \\
\hline Vaginal delivery ${ }^{139}$ & Polycythemia ${ }^{92,112,148}$ \\
\hline Cesarean section ${ }^{29}$ & Red Cell Transfusion ${ }^{106,150-155}$ \\
\hline Meconium aspiration ${ }^{106}$ & Immunoglobuline treatment for hemolytic \\
\hline Asphyxia/Low Apgars ${ }^{82,97,106,114,125,138,139}$ & anemia $^{156-158}$ \\
\hline Antenatal glucocorticoids ${ }^{138,139}$ & Exchange transfusion ${ }^{92,111,114,159}$ \\
\hline Surfactant ${ }^{123}$ & Presence of umbilical catheters ${ }^{82,111}$ \\
\hline African American descent ${ }^{25,84,140}$ & Absence of an umbilical catheter ${ }^{139}$ \\
\hline Male sex ${ }^{125,136,140,141}$ & Inhibitors of gastric acid secretion ${ }^{160-162}$ \\
\hline Small for Gestational Age $\mathrm{e}^{28,142-144}$ & Prolonged empirical antibiotics ${ }^{163-165}$ \\
\hline \multirow{2}{*}{$\begin{array}{l}\text { Congenital digestive, musculosceletal, or } \\
\text { multiple anomalies }{ }^{27,82}\end{array}$} & Formula feeding ${ }^{97,112}$ \\
\hline & Breastmilk fortifier ${ }^{136}$ \\
\hline
\end{tabular}

> Premature rupture of membranes (PROM) and chorioamnionitis increase the risk of premature birth. ${ }^{166}$ Several studies, including one meta-analysis, have also indicated that it independently increases the risk of NEC and/or SIP. ${ }^{114,131-134}$ Others found no association of the severity of chorioamnionitis ${ }^{167}$ or presence of histological chorioamnionitis ${ }^{166}$ with NEC. NEC occasionally occurs in infants, who have never been fed. ${ }^{25,92,144}$ It has been speculated that infected amniotic fluid could act as substrate. ${ }^{23}$ Infected amniotic fluid is also involved in the "two-hit hypothesis", which implies that intrauterine exposure to inflammatory stimuli may "prime" cells of the innate immunity and make them more reactive, so that, on encounter with inflammatory stimuli peri- or postnatally they, may react with exaggerated production of proinflammatory cytokines involved in the pathogenesis of NEC. ${ }^{19}$ 
Antenatal steroids are, together with routine administration of synthetic surfactant at birth, part of the proactive approach to perinatal care that has developed during the last decades. ${ }^{25,83,99}$ A meta-analysis from 2006, found a clear protective effect of antenatal corticosteroids against NEC. ${ }^{168}$ A later systematic review found reduced risk for combined serious outcome including NEC, with repeat doses of antenatal steroids compared to a single dose, ${ }^{169}$ and a meta-analysis from 2013 found no significant difference between sorts of corticosteroids, ways of administration or regimen, although with just one or two studies addressing each outcome. ${ }^{170}$

Caesarean section. Given the importance of colonisation with normal intestinal flora for the maturation of the neonatal intestine, caesarean section might be expected to increase the risk for NEC. The suspicion was raised in one small study of NEC in 14 term infants where it was noted that all but one were delivered by CS, that half of the cases lacked obvious predisposing factors for NEC, and that an increasing frequency of CS seemed to be paralleled by an increasing incidence of NEC in term infants.. ${ }^{29}$ Others have instead found vaginal delivery a risk factor for NEC in the premature ${ }^{27,139}$ or no significant difference ${ }^{86}$.

Congenital heart disease. Major heart disease is a well- established risk factor for NEC in mature infants, $93,112,115,149$ but may also influence the risk of very low birthweight infants $(<1500 \mathrm{~g})$ according to two large multicentre studies from the US, investigating NEC in infants with atrial and ventricular septum defects $1997-2010^{87}$ and serious congenital heart disease in 2006-2011145 respectively.

Patent ductus arteriosus (PDA). The role of a PDA in NEC is not quite clear. A hemodynamically significant PDA results in reduced blood flow to the mesenteric vascular bed and so does medical treatment with indomethacin. ${ }^{146}$ Surgery for PDA, as well as Indomethacin, has emerged as a risk factor for NEC in some studies. ${ }^{82,136,146,167}$ A meta-analysis from 2007 found an increased risk of NEC with a long indomethacin course compared to a short one. ${ }^{171}$ 
Blood transfusion. Transfusion of red blood cells has long been suspected to contribute to the occurrence or severity of NEC, ${ }^{150-155,172}$ One proposed mechanism is that a sudden increase in blood viscosity would reduce mesenteric blood flow and, in case of simultaneous enteral feeding, cause a relative ischemia. ${ }^{30}$ An alternative explanation is an immunologic influence working through mesenteric arterial reactivity and nitric oxide pathways as investigated in premature lambs. ${ }^{173}$ So far, however, evidence has been equivocal, ${ }^{174,175}$ and a recent meta-analysis, found that the quality of the studies on transfusion induced NEC was generally low.

Infant formula: Apart from acting as bacterial substrate, infant formula, compared to human milk, contains more free fatty acids, which have been shown to be cytotoxic in high concentrations, when digested in vitro. ${ }^{176}$ Breast milk, in contrast, has been found to be protective against NEC. ${ }^{177-183}$ Bioactive components of the milk and maternal immunoglobulins contribute to immune modulation, stimulation of gut colonisation with beneficial microorganisms, and defence against pathogens through bacteriostatic-, bactericidal-, and neutralising effects, preventing attachment and invasion of pathogens to the intestinal mucosa. Literature on breast milk components and their beneficial effects is abundant, and has been summarised in several reviews with different perspectives. ${ }^{16,184-186}$ Despite great support for the protective role of breast milk compared to formula feeding, there are however studies, where no such difference was demonstrated. ${ }^{86,113,149}$

Empirical antibiotics. A systematic review in 2001 suggested that prophylactic enteral administration of antibiotics reduced the incidence of NEC in low birth weight infants ${ }^{187}$, but later studies have indicated that the duration of empirical antibiotics in premature neonates without a positive blood culture is associated with an increasing incidence of NEC and other adverse effect such as late onset sepsis and death. ${ }^{163-165}$

H2-blockers, routinely used in neonatal intensive care, may increase the risk of NEC according to observational studies. ${ }^{160-162}$ Faecal microbial diversity seems to be reduced and the microbial pattern shifted towards proteobacteria. ${ }^{14}$ The risk of NEC may also be increased by direct effects of H2-blockers on the immune system and decreased intestinal motility. ${ }^{161,188}$ 


\section{Prevention}

Quality improvement projects including scheduled feeding and the use of human milk, ${ }^{189,190}$ conservative feeding guidelines during blood transfusions, and indomethacin treatment, and restrictive use of H2-blockers ${ }^{190}$ seem to be able to reduce the incidence of NEC in institutions. As each program included a combination of preventive measures, it is, however, difficult to discern which ones had effect.

As for feeding schedules, systematic reviews with meta-analyses of randomised and quasi randomised studies have failed to show any difference in NEC between early or late introduction of progressive enteral feeding ${ }^{191}$, trophic feeding compared to enteral fasting, ${ }^{192}$ or slow versus faster advancement of feeding. ${ }^{193}$ Among the studies included in the first two reviews, there were, however, few participants of gestational age $<28$ weeks or birthweight $<1000 \mathrm{~g}$. It has been proposed that scheduled feeding per se, regardless of protocol, may reduce NEC through enhancing the awareness of feeding and feeding volumes. ${ }^{194}$

Since microbial imbalance, dysbiosis, is thought to play an important role in NEC, ${ }^{14,195}$ the potential of probiotics to promote colonisation with beneficial bacteria and thereby prevent NEC has been investigated. After initial uncertainty about efficacy and safety of probiotics, it was concluded in a recent systematic review, that enteral supplementation with probiotics prevented NEC, especially when multiple strains were combined, and, although not systematically analysed, no adverse effects were noted in the included studies. The optimal combination of bacterial strains is, however, not settled. ${ }^{196}$

\section{Treatment}

Medical management of NEC consists of bowel rest, antibiotics, gastric decompression and supportive care including ventilatory support, fluid resuscitation, inotropic support, and correction of acid-base imbalance, coagulopathy and thrombocytopenia, as well as close surveillance with clinical evaluation, monitoring of laboratory status, and imaging, ${ }^{197,198}$ in order to detect deterioration and prevent delay of surgical intervention when needed.

Surgical treatment consists in laparotomy with resection of necrotic bowel or percutaneous peritoneal drainage, frequently followed by laparotomy. The frequency of surgical treatment varies between populations. Holman reported 
$27 \%, 31 \%$ in birthweights $<1500 \mathrm{~g}$. Around $50 \%$ has also been reported. $99,199,200$ Heida found decreasing frequencies of surgical interventions from $53 \%$ in $2005-$ 2007 to $29 \%$ in 2011-2013, with pneumoperitoneum increasing its share of indications for surgery from 47 to $63 \% .^{201}$

* Indications for Surgery

The only generally accepted indication for surgery is $\mathrm{PP}$ on $\mathrm{AR}, 70,202,203$ as a sign of intestinal perforation. Especially in the extremely low birth weight infants, however, the sensitivity of radiographic signs is low, $26,39 \mathrm{PP}$ is known to be missing in a great proportion of infants with perforated NEC. ${ }^{11,37,75}$ Other signs, such as persistent/fixed loop and PVG are discussed. ${ }^{23,46,56,57,59,79,204}$ Although PVG on AR has been associated with poor outcome, ${ }^{56}$ it has also been suggested that not PVG, but severity of NEC, is associated with the need for surgical intervention. ${ }^{23}$ Ultrasonographic signs that may indicate intestinal necrosis and need for surgery include localized and/or turbid fluid $53,68,72$ and absent perfusion with reduced peristalsis. ${ }^{71}$

Clinical indications for surgical intervention include deterioration in spite of maximal medical treatment, abdominal erythema or a palpable abdominal mass. ${ }^{144,199,203}$ The potential of biomarkers to distinguish serious NEC, that may require surgery, from milder disease, is being explored. ${ }^{205}$

Blakely reported that, in 156 infants undergoing laparotomy or drainage for NEC or SIP, the indication was PP in $64 \%$, clinical deterioration despite medical therapy in $66 \%$, PVG in $14 \%$, abdominal wall erythema in $28 \%$, infected ascites in $5 \%$, and other factors in $26 \% .33$ Obviously one individual could have more than one indication.

Tepas et.al. investigated a combination of metabolic parameters and found that timing surgery according to seven criteria of metabolic derangement (MD7), rendered better outcome than waiting for free gas on AR to appear. ${ }^{206} \mathrm{He}$ et.al reported that, in infants without $\mathrm{PP}$, abdominal erythema, elevated C-reactive protein, and, especially, what they called "a critical imaging report", were all independent predictors for the need of surgery, indicated by a deteriorating general condition and failure to respond to conservative management. The critical imaging report was defined as any finding of persistent loop or PVG on AR or sonographic evidence of thickening of the bowel wall, absent peristalsis, 
or echogenic, free intraabdominal fluid. Of these signs, PVG on AR had the highest specificity, and absent peristalsis on US the highest sensitivity. ${ }^{59}$

\section{Outcome}

Like incidence of NEC, mortality rates vary widely between studies. In populations not restricted to a particular range of gestational age or birth weight, mortality rates of 12 to $38,5 \%$ have been reported $25,28,84,85,140,201,207,208$ with seemingly lower rates in later publication years. After surgical treatment, mortality may be considerably higher. ${ }^{144,207,209}$ Reported risk factors for death in NEC include low birth weight, 85,210 early onset and bleeding tendency, ${ }^{28}$ hispanic etnicity, and number of ICD-diagnoses..$^{85}$ Extension of necrotic bowel, sepsis and organ failure also contribute to adverse outcome. ${ }^{33,207}$ Holman et al found a decreasing NEC mortality rate 1979 through 1986, which they attributed to improved neonatal intensive care, but increasing rates 1986 through 1992, despite improved over-all early survival. ${ }^{83}$ Luig and Lui ${ }^{99}$ found mainly unchanged mortality rates 1986-1999, as did Heida in 2005-2013.

Long term complications include strictures of the bowel in $20--57 \%$ of survivors, ${ }^{24,113}$ adhesions, enteric fistulas, intestinal insufficiency, and neurodevelopmental impairment, as well as secondary complications due to parenteral nutrition and prolonged intensive care. $2,10,207,211$

Data from Canada and Sweden show that $73-83 \%$ of survivors after extremely preterm birth have no severe neurodevelopmental impairment. ${ }^{212,213}$ NEC, however, significantly increases the risk. ${ }^{212-214}$

Stricture of the bowel may occur after medical NEC, sometimes even in not confirmed cases, ${ }^{12}$ but is more common after surgical NEC. In a Chinese study of 464 neonates with NEC, post-NEC strictures were predicted by a pronounced inflammatory response in the acute phase, expressed as a prolonged and accentuated elevation of C-reactive protein, thrombocytopenia, and clinical signs of peritonitis.

Intestinal insufficiency, may result from bowel resection for NEC, but also from NEC itself. Defined as dependency of total parenteral nutrition after 90 days, an overall frequency of about $15 \%$ has been reported, ${ }^{215,216}$ considerably higher at 42 days ${ }^{215}$ and after surgery. ${ }^{215,216}$ Risk factors, in addition to NEC, included low birthweight, extent of small intestine resection, ventilator use at diagnosis of NEC, use of antibiotics at diagnosis of NEC, and gram negative bacteremia. 215,216 


\section{Aims of the present work}

\section{Register studies:}

I. To investigate temporal, seasonal, and geographic variations in the incidence of necrotising enterocolitis (NEC), and its relation to early infant survival in the Swedish population, as well as in subgroups based on gestational age, birth weight, and sex.

II. To investigate the occurrence of space-time clusters of NEC in the Swedish population and the development of clustering over time, using maternal residential municipality and delivery hospital to define closeness in space.

III. To analyse differences in maternal, fetal, gestational, and perinatal factors among NEC cases and matched controls, and identify associations of these factors with NEC.

IV. To analyse the incidence of intestinal failure and its previously suggested risk factors in infants with a history of NEC compared to matched controls.

\section{Multispecialist survey}

V. To investigate current practices and perceptions of imaging in the management of NEC, as reported by involved specialists, put them in the context of current literature, and find areas in need of further study. 


\section{Material and Methods}

\section{Epidemiological Studies (papers I-IV)}

Anonymised data on the national birth cohorts of 1987 through 2009 was obtained from the following registers held by the Swedish Board of Health and Welfare: National Patient Register (NPR), the Medical Birth Register (MBR) ${ }^{1}$, and the Cause of Death Register (CDR)2 and supplemented with socioeconomic data from Statistics Sweden.

* Case Ascertainment

All posts in the registers containing a discharge diagnosis code of NEC, according to the World Health Organization (WHO) International Classification of Disease, $9^{\text {th }}$ or $10^{\text {th }}$ revision, (ICD9 or ICD10), i.e. 777F or P77 respectively, were identified. Posts containing a full personal identification number, allowing linkage between registers, belonged to 794 individuals, of which 720 could also be found with their identification number in the MBR.

Of the remaining posts, most could be traced and linked to unique individuals using information on sex, date of birth, dates of discharge and admission, place of residency, diagnoses other than NEC, as well as knowledge of the referral system between hospitals, resulting in an estimation of a total of 920 individuals with NEC. 112 of these could, however, not be reliably linked to any post in the MBR, and were therefore excluded from the incidence studies (paper I and II) as well as from the case-control studies (paper III and IV). 88 individuals could with reasonable certainty be linked to unique individuals in the MBR, although the personal identification number was missing in the NPR registrations. These were included in the incidence studies but not in the case-control studies. The incidence studies thus counted 808 cases of NEC of which 720 were included in the case-control studies.

${ }^{1}$ Abbreviated SMB in Paper I.

${ }^{2}$ Abbreviated NCD in Paper I 


\section{Case Ascertainment Flow Chart}

\section{Medical Birth Register MBR}

488 patients with NEC diagnosis

22 without personal identification

number

\section{National Patients Register NPR}

In patients with NEC diagnosis 1987 - 2009:

- 1,494 hospitalisations

- 576 without personal identification number

- 63 without date of birth

Out patients with NEC diagnosis 2001 - 2009:

- 305 visits

- 70 without personal identification number

- 4 without date of birth

112 deaths with NEC as principal or contributing cause

8 without personal identification number

Case-control studies (paper III and IV): $\mathbf{7 2 0}$ cases with full identity information retrieved in the MBR.

1-6 controls for each case, matched for gestational age and year of birth.

$\Rightarrow 3,664$ controls
794 unique individuals identified by their personal identification number
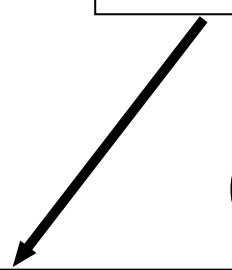

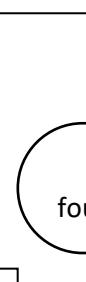

74 cases not found in the MBR
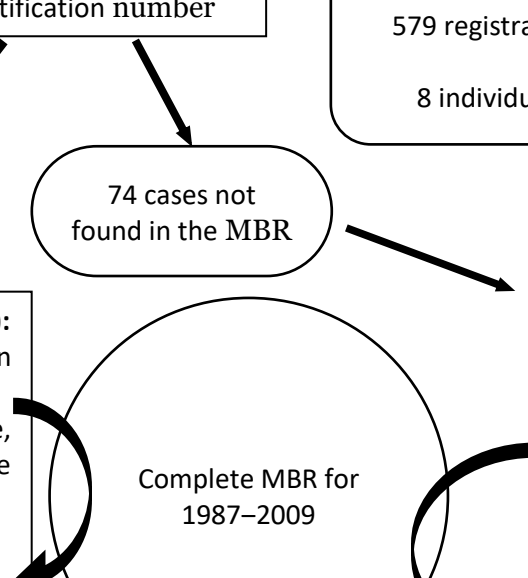

579 registrations

8 individuals from NCD

\section{Lacking personal identification} number

tions from NPR

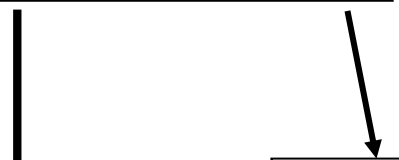

Excluded:

67 posts without date of birth; could not be traced further

Manual identification process:

291 probable individuals based on date of birth, sex, place of residency, diagnoses other than NEC and plausible chain of admissions.

99 are with reasonable certainty identical with individuals already identified as cases.

80 are with reasonable certainty identical with other individuals in the MBR, 14 of which have a diagnosis of NEC but no personal identification number (in all 22 posts, of which 8 remain).

112 cannot be reliably identified in the MBR.

\section{0 cases and 3,656 controls} Information from the MBR, NPR and NCD 1987-2011 for cases and controls
Incidence studies (paper I and II):

720 cases with full identity information

80 manually identified cases

8 cases with NEC diagnosis in MBR

$$
\Rightarrow 808 \text { cases }
$$

Complete MBR 1987 - 2009 as background population 
Subgroups According to Gestational Age and Birthweight Since the incidence rate, presentation and risk factor patterns are known to vary with gestational age and birthweight, the population was divided in subgroups according to these parameters with limits chosen to fit the definitions of ICD10.

\begin{tabular}{cc} 
Subgroups Defined by & Gestational age \\
\hline Extremely premature & $<28$ full weeks \\
Very premature & $28-31$ full weeks \\
Moderately premature & $32-36$ full weeks \\
Full term & $\geq 37$ full weeks
\end{tabular}

* Handling of Missing Data

\begin{tabular}{cc}
\multicolumn{2}{c}{ Subgroups Defined by Birth Weight } \\
\hline Most Extremely Low Birth Weight & $<750 \mathrm{~g}$ \\
Extremely Low Birth Weight & $750-999 \mathrm{~g}$ \\
Very Low Birth Weight & $1000-1499 \mathrm{~g}$ \\
Moderately Low Birth Weight & $1500-2499 \mathrm{~g}$ \\
Normal Birth Weight & $\geq 2500 \mathrm{~g}$
\end{tabular}

In order to estimate the influence of missing data on the results, the occurrence of codes for diagnoses "highly premature" or "very low birth weight" (765A according to ICD-9 or P070 or P072 according to ICD-10), "other" premature or low birth weight (ICD-9 765B; ICD-10 P071 or P073), and "small for gestational age" (ICD-9 764A, 764B, 764D, 764E, or 764X; ICD-10 P050 or P051), abdominal surgery as well as in-hospital deaths, was compared for the children with and without traceable perinatal data in the SMB and for hospitalisations with and without a valid personal identification number.

In the risk factor analysis, some missing information would cause the loss of a substantial number of observations in the multivariable analyses. Such missing values were found in birthweight ( $\mathrm{n}=90)$, length at birth ( $\mathrm{n}=932)$, Apgar score at 1 minute $(\mathrm{n}=174)$, Apgar score at 5 minutes $(\mathrm{n}=197)$, Apgar score at 10 minutes $(n=627)$, maternal weight $(n=1,245)$, and maternal disposable income $(n=47)$. After checking for missingness at random the missing values were supplemented through multiple imputations. ${ }^{217}$

* Incidence and Trends

The complete extract from the MBR 1987-2009 was used as background population to 808 cases of NEC, of which 88 had been manually identified as described above.

Cases and background population characteristics were analysed with descriptive statistics. Poisson regression was used for covariations and trends, reporting results as IRR. The term annual IRR was used to describe the strength of trends over time. 


\section{Seasonality and Clustering}

The same background population and NEC cases were used for analysis of seasonal variation and the occurrence of space time clustering in NEC incidence. Seasonal variation was analysed in the complete monthly time series by investigating for the presence of harmonic cyclicity with auto correlation. A seasonal subseries plot was used to graphically identify the eventual peak and trough (paper I).

The Knox space-time cluster analysis and the Kulldorff's space-time permutation scan were used to identify significant space-time clustering of NEC. Delivery hospital and the mother's residential municipality were used to define closeness in space (paper II).

\section{Risk Factors}

For the analysis of risk factors of NEC, the 720 cases with full identity information in the MBR were used with 1-6 controls, matched for gestational age in days and year of birth. Due to limited numbers of available controls especially in the most premature, the desired number of 6 controls was not reached for all cases, but all cases had at least one control, and $87 \%$ had 3 controls or more.

Predisposing factors for NEC related to the mother, pregnancy, delivery, infant and perinatal course were sought for in routinely registered information in the MBR and the socioeconomic data from Statistics Sweden, as well as among diagnose codes and procedure codes in the NPR and MBR. Potential risk factors were tested with univariable and multivariable logistic regression in the entire population and in subgroups according to gestational age. The final set of variables included in the models was chosen through a combination of Least Angle Regression and inclusion of suspected risk factors according to previous publications. Variables deemed to be spuriously associated with NEC, showing signs of multicollinearity, or giving unstable models because of few cases in some strata, were sought for and removed.

Since NEC rarely occurs before one week of age, a variable representing 7 days survival, regarded as a prerequisite for NEC, was included in all regressions, univariable as well as multivariable. So were the matching variables, gestational age in days and birth year, in order to minimise any bias induced by the uneven 
distribution of controls. Results were reported as odds ratio (OR) with a 95\% confidence interval.

* Intestinal Failure

Intestinal failure was defined as a diagnosis of intestinal malabsorption or postoperative malabsorption/short bowel syndrome (ICD9 codes 579D, 579W, or 579 X or ICD10 codes K904, K908, K909, or K912) or a procedural code of total parenteral nutrition (9915, according to the 1985 version of classifications of non-surgical procedures, or DV055, according to the 1997 version).

Procedural codes searched for to identify relevant abdominal surgery included 4010, 4030, 4041, 4047, 4630, 4631, 464, 465, 4660, 4661, 470, 471, 4721, according to the 1985 codes of surgical procedures and JAH00, JAK00, JAK03, JFB, JFC, JFF, JFH, TJA10, and TJA20, according to the 1997 version. Additionally, reversion of stomas, 4664, 4665, and JFG00-JFG50, were identified and used in supplementary analyses to find patients whose primary operation might have been during a hospitalisation with missing identity information.

The study period was divided into birth cohorts based on quartiles of the study population: 1987-1993, 1993-2001, 2002-2006, and 2007-2009. The influence of gestational age, birthweight, intrauterine growth restriction (expressed as small for gestational age, SGA), low apgar scorings, place and year of birth, maternal smoking, maternal level of education, and abdominal surgery on the risk of NEC cases and controls to develop intestinal failure between two weeks and two years of age was investigated with univariable and multivariable Cox regressions.

\section{Supplementary Analyses}

Supplementary, not published analyses on surgery, intestinal failure, and mortality and their trends over time were carried out with descriptive methods, Poisson regression and logistic regression. 


\section{Survey on the Role of Imaging in the Management of NEC, paper V}

* Preparation of the Questionnaires

The selection of questions for the survey was guided by literature studies, interviews with neonatologists and paediatric surgeons, and a pilot survey among Swedish and American paediatric radiologists. The final questionnaires, one intended for radiologists, the other for clinicians, i.e. neonatologists and paediatric surgeons, are presented as Appendix 1 and 2 of paper $\mathrm{V}$.

* Invitation of Respondents

The questionnaires were web-based and available through a link that was distributed by e-mail through European and American specialist organisations for neonatology, paediatric surgery, and paediatric radiology, members of which were from all over the world. The associations approached were the European Society of Paediatric Radiology (ESPR), the Society for Pediatric Radiology (SPR), Svensk Förening för Pediatrisk Radiologi (SFPR), the European Society for Paediatric Research/European Society for Neonatology (ESPR/ESN), the British Association of Perinatal Medicine (BAPM), the American Academy of Pediatrics (AAP), the European Paediatric Surgery Association (EuPSA), and the American Pediatric Surgery Association (APSA). In order to increase the response rate, distribution of the link through personal communication was also accepted.

* Distribution of Respondents

Variation in policies regarding mediation of questionnaires and mass e-mailing within the specialist organisations resulted in an uneven geographical distribution of respondents within specialties with a predominance of radiologists from the USA, Canada, and Sweden and neonatologists from the UK, whereas paediatric surgeons were more scattered, although mostly found in Europe and the Middle East. See table 7.

Analysis of Proportions of Respondents

With the intent to identify and describe, on the one hand, areas of agreement between respondents and, on the other, issues in need of further clarification and study, results were analysed using simple proportion estimations with $95 \%$ confidence intervals. Where differences between specialties were found, analyses were repeated without dominant groups, e.g. radiologists from North 
America and Neonatologists from the British Islands, attempting to discern whether a detected difference was more likely due to geographical variations in clinical traditions than diverging perceptions between specialties.

Table 7: Distribution of respondents between countries and specialties

\begin{tabular}{|c|c|c|c|c|c|}
\hline Country & Radiologists & Neonatologists & Surgeons & Double* & Total \\
\hline Australia & 1 & 3 & 0 & 0 & 4 \\
\hline Austria & 1 & 1 & 1 & 0 & 3 \\
\hline Belgium & 0 & 0 & 1 & 0 & 1 \\
\hline Bulgaria & 0 & 1 & 1 & 0 & 2 \\
\hline Canada & 8 & 1 & 0 & 0 & 9 \\
\hline Chile & 1 & 0 & 0 & 0 & 1 \\
\hline Czech Republic & 1 & 0 & 0 & 1 & 2 \\
\hline Denmark & 0 & 4 & 0 & 0 & 4 \\
\hline Egypt & 0 & 0 & 1 & 0 & 1 \\
\hline Finland & 1 & 0 & 1 & 0 & 2 \\
\hline France & 0 & 1 & 4 & 2 & 7 \\
\hline Germany & 0 & 4 & 1 & 1 & 6 \\
\hline Greece & 0 & 0 & 1 & 0 & 1 \\
\hline Guernsey & 0 & 1 & 0 & 0 & 1 \\
\hline Hungary & 0 & 0 & 3 & 0 & 3 \\
\hline Ireland & 0 & 4 & 1 & 0 & 5 \\
\hline Israel & 0 & 3 & 2 & 0 & 5 \\
\hline Italy & 0 & 1 & 5 & 0 & 6 \\
\hline Japan & 0 & 1 & 0 & 0 & 1 \\
\hline Kenya & 1 & 0 & 0 & 0 & 1 \\
\hline Latvia & 0 & 0 & 2 & 0 & 2 \\
\hline Mexico & 0 & 0 & 1 & 0 & 1 \\
\hline Netherlands & 2 & 5 & 2 & 0 & 9 \\
\hline New Zealand & 1 & 1 & 0 & 0 & 2 \\
\hline Norway & 0 & 0 & 1 & 0 & 1 \\
\hline Oman & 1 & 0 & 0 & 0 & 1 \\
\hline Philippines & 1 & 0 & 0 & 0 & 1 \\
\hline Poland & 0 & 0 & 1 & 0 & 1 \\
\hline Portugal & 0 & 0 & 2 & 1 & 3 \\
\hline Romania & 0 & 0 & 3 & 0 & 3 \\
\hline Saudi Arabia & 0 & 0 & 2 & 1 & 3 \\
\hline Serbia & 0 & 0 & 0 & 1 & 1 \\
\hline Slovenia & 1 & 0 & 1 & 0 & 2 \\
\hline South Korea & 1 & 0 & 1 & 0 & 2 \\
\hline Spain & 1 & 3 & 2 & 0 & 6 \\
\hline Sweden & 8 & 6 & 3 & 0 & 17 \\
\hline Taiwan & 0 & 1 & 0 & 0 & 1 \\
\hline Turkey & 0 & 1 & 4 & 0 & 5 \\
\hline UK & 2 & 25 & 2 & 0 & 29 \\
\hline USA & 39 & 2 & 1 & 0 & 42 \\
\hline Unknown & 3 & 1 & 1 & 0 & 5 \\
\hline Total & 74 & 70 & 51 & 7 & 202 \\
\hline
\end{tabular}




\section{Results}

\section{Incidence of Necrotising Enterocolitis (paper I and II):}

The incidence of necrotising enterocolitis (NEC) in the general population of Sweden 1987-2009 was 0.34 per 1,000 live births (0.38 including presumed cases with insufficient information to allow identification) with an increasing trend from 0.26 in 1987-1992 to 0.57 in 2005-2009, annual IRR 1.05 (1.04-1.06), 95\% CI within brackets.

The incidence in infants with birth weights $<750 \mathrm{~g}$ was 53.1 per 1,000 live births, increasing from 27.2 in 1987-1992 to 89.5 in 2005-2009, annual IRR 1.08 (1.051.11).

In the general population and in all sub-groups, except in gestational ages $<28$ weeks and birth weights $<750 \mathrm{~g}$, the incidence curve was J-shaped with an initial decrease followed by an increase, reaching its turning point at a slightly earlier time with increasing immaturity. The increase was paralleled by a generally increasing early infant survival in all gestational ages.

$82 \%$ of NEC cases were preterm, increasing from $70 \%$ in $1987-1992$ to $86 \%$ in 2005-2009.

Apart from a higher incidence in Stockholm compared to the rest of the country, no regional differences were identified.

There was an overall seasonality of NEC with a peak in November and a trough in May. Evidence of space-time interaction was found in the hospital environment but not on community level. Using Knox time-space cluster analysis, based on pairs of cases classified as born close or distant in space as well as in time, clustering was identified during 1987-1997 but not during 19982009. Using the Kulldorff's space-time permutation scan, seven significant clusters of 2-5 cases within 1-24 days were identified, three of which occurred during the first sub period and four during the second.

\section{Risk factors of necrotising enterocolitis (paper III):}

In the following, all associations refer to the multivariable regressions.

7 days survival, assumed to be a prerequisite for NEC, was higher in cases than in controls, especially in gestational ages $<28$ weeks. There was, however, also early mortality in NEC cases of all gestational ages, implicating the occurrence of early onset NEC. 
Study Population as a Whole

In the study population as a whole, there were positive associations of NEC with being born in Stockholm, OR 1.87 (1.55-2.27), $\mathrm{p}<0.001$, isoimmunisation, OR 1.63 (1.10-2.43), $\mathrm{p}=0.016$, fetal distress, OR 1.44 (1.14-1.80), $\mathrm{p}=0.002$, delivery by caesarean section, OR 1.53 (1.25-1.89), $\mathrm{p}<0.001$, without significant difference if CS was elective or finalised an initially spontaneous delivery, bacterial infection, including sepsis, OR 2.53 (2.06-3.12), p<0.001, erythrocyte transfusion OR 1.34 (1.05-1.73), $\mathrm{p}=0.021$, persistent ductus arteriosus, OR 1.70 (1.33-2.16), $\mathrm{p}<0.001$, cardiac malformation, OR 1.64 (1.11-2.41), $\mathrm{p}=0.012$, gastrointestinal malformation, OR 2.77 (1.52-5.06), $\mathrm{p}=0.001$, and chromosomal abnormality 2.55 (1.29-5.02), $\mathrm{p}=0.007$. Negative associations were found with maternal bodyweight in kg, OR 0.99 (0.98-1.00), $\mathrm{p}=0.032$, maternal pre-eclampsia, OR 0.68 $(0.52-0.89), \mathrm{p}=0.005$, maternal urinary infection during pregnancy, OR 0.71 (0.53-0.95), $\mathrm{p}=0.019$, premature rupture of the membranes, OR 0.62 (0.49-0.80), $\mathrm{p}<0.001$, infant birthweight, OR $0.93(0.90-0.96)$ per $100 \mathrm{~g}, \mathrm{p}<0.001$, and neonatal icterus, OR 0.57 (0.46-0.69), $\mathrm{p}<0.001$.

Of these, maternal bodyweight and pre-eclampsia showed uniform tendencies in all subgroups, but, except for maternal weight in gestational ages $<28$ weeks, the associations were not significant in any of the subgroups.

\section{* Subgroups}

A few factors did not reach significance in the population as a whole but only in certain subgroups. Being small for gestational age showed an independent positive association with NEC in term infants only, OR 6.52 (2.27-18.73), $\mathrm{p}=0.001$, and a non-significant, positive tendency in GA 32-36 w. Apgar $<7$ at 5 minutes was independently and positively associated with NEC in GA 32-36 w only, OR 3.24 (1.28-8.17), p=0.013, but with a uniform tendency in all subgroups except $\mathrm{GA}<28 \mathrm{w}$.

The positive association with fetal distress was not seen in $\mathrm{GA}<28 \mathrm{w}$, and was significant only in $\mathrm{GA} \geq 32 \mathrm{w}$ (term and near-term infants). The pattern for caesarean section was similar. Cardiac malformation was positively associated with NEC in GA $\geq 32 \mathrm{w}$ but not in lower gestational ages. The positive association with erythrocyte transfusion was confined to GA $28-36 \mathrm{w}$, the variable being excluded from the term subgroup because of too small numbers and showing a non-significant negative tendency in $\mathrm{GA}<28 \mathrm{w}$. 
While isoimmunisation showed a uniform, positive tendency in all subgroups, although significant only in the term subgroup and GA 28-31 w, neonatal icterus was negatively associated with NEC in GA $\leq 36 \mathrm{w}$.

Relation to other Morbidities Specific to the Premature There was an independent, positive association with intracranial bleeding, predominantly intraventricular haemorrhage, OR 1.74 (1.33-2.29), $\mathrm{p}<0.001$, and a negative one with bronchopulmonary dysplasia, OR $0.62(0.46-0.84), \mathrm{p}=0.002$.

\section{Outcome (paper IV)}

Early surgery, defined as at least one operation coded according to the defined procedural codes for relevant abdominal surgery in the PTR within three months of birth (120 cases, $17 \%$ ) or in the MBR (adding 10 NEC cases) or reversal of stoma within 18 months of age (adding 40 NEC cases), occurred in 170 NEC cases, $24 \%(21-27 \%)$, and 50 controls, $1 \%(1-2 \%)$.

In NEC cases, after adjusting for sex, gestational age, and birthweight, there was a slightly positive trend for early surgery over time: annual IRR 1.03 (1.01-1.06), $\mathrm{p}=0.011$. In controls, the trend was negative: annual IRR $0.96(0.92-1.00)$, $\mathrm{p}=0.031$.

Intestinal failure with onset before two years of age was found in $6 \%$ of NEC cases and $0.4 \%$ of controls, $\mathrm{p}<0.001$. In NEC patients subjected to early abdominal surgery, the proportion of IF was $14 \%$ and in those without indication of early surgery it was 3\%. Among controls without NEC, all patients with IF were premature, $63 \%$ (45-84\%) below 28 w GA, but 10 out of 16 had no history of abdominal surgery. Among NEC cases, $5 \%$ of patients with IF were full term and 51\% (36-66\%) below 28 w GA.

Independent risk factors for intestinal failure were a history of NEC, a history of abdominal surgery early in life, extreme prematurity, fetal growth restriction (being small for gestational age) and a later year of birth.

After adjusting for sex, gestational age, fetal growth restriction, and early surgery, there was a positive trend for IF over time with annual IRR 1.23 (1.121.34), $\mathrm{p}<0.001$, for NEC cases and 1.15 (1.03-1.27), $\mathrm{p}=0.012$, for controls.

Death within four weeks of birth occurred in 107 NEC cases and 307 controls, corresponding to $15 \%(12-18 \%)$ and $8 \%(8-9 \%)$ respectively, $\mathrm{p}<0.001$. NEC related mortality, i.e. with NEC stated as a principal, underlying or contributing 
cause of death, was found in 105 patients, which rendered an overall NEC related mortality in NEC cases of $15 \%(12-17 \%)$, without difference between cases subjected to early abdominal surgery, $14 \%$ (9-20\%), and not $15 \%(12-18 \%)$. NEC-related mortality was lower during the last sub-period but without significant difference to any other sub-period and without significant trend over time. It occurred within the first week in $23 \%$, within four weeks in $67 \%$, and within three months in $90 \%$. Of the 105 with nec related mortality, 23 had had early abdominal surgery. In no NEC case or control was any of the diagnose codes defining intestinal insufficiency among the causes of death, and only two of the those with NEC among their causes of death had IF. There was no association between IF and mortality within two years of birth.

\section{Missing data}

Because of discrepancies between the ICD9 and ICD10, diagnoses of prematurity in the following tables include diagnoses of low gestational age as well as low birthweight: High grade prematurity includes ICD9 765A and ICD10 P070 and P072. Other prematurity includes ICD9 765B and ICD10 P071 and P073. SGA includes ICD9 764A, 764B, 764D, 764E, and 764X and ICD10 P050 and P051.

Hospitalisations without personal identification number

Out of 1494 hospitalisations in the NPR, personal identification number was missing in 576, of which 63 also lacked information on date of birth. Prematurity diagnoses and death at discharge were more common in hospitalisations where the personal identification number was missing than where it was present. Please note that each individual can have many hospitalisations, with, as well as without, complete identification information.

Comparison of hospitalisations with and without personal identification number

Diagnosis of...

\begin{tabular}{l} 
\\
\hline High grade prematurity \\
Other prematurity \\
Any degree of prematurity \\
SGA \\
Abdominal surgery*
\end{tabular}

Death

* Reversal of stoma not included
With identification, $\mathrm{N}=918$

$\mathrm{n}(\%)$

$296(32 \%)$

$320(35 \%)$

$581(63 \%)$

$79(9 \%)$

$128(14 \%)$

$55(6 \%)$
Lacking identification,

$\mathrm{N}=576 \quad \mathrm{p}$

$\mathrm{n}(\%)$

$\begin{array}{cr}221(38 \%) & 0.015 \\ 237(41 \%) & 0.014 \\ 433(75 \%) & <0.001 \\ 61(11 \%) & 0.200 \\ 80(14 \%) & 0.976 \\ 89(15 \%) & <0.001\end{array}$


Manually identified individuals

The efforts for paper I to identify individuals among the hospitalisations without a personal identification number resulted in 920 presumed individuals, for whom data of 808 could with reasonable certainty be retrieved from the MBR. Comparing these 808 with the 112 that could not be reliably identified, prematurity diagnoses were more common among NEC patients found in the MBR than among those not found, without significant differences in SGA diagnoses or death at discharge.

\begin{tabular}{lccr}
$\begin{array}{l}\text { Comparison of presumed individuals identified and not identified in the MBR } \\
\text { Diagnosis of... }\end{array}$ & $\begin{array}{c}\text { Idenified, N=808 } \\
\text { Not identified, N=112 }\end{array}$ \\
\cline { 2 - 4 } High grade prematurity & $347(42 \%)$ & $43(38 \%)$ & 0.361 \\
Other prematurity & $377(47 \%)$ & $33(29 \%)$ & 0.001 \\
Any degree of prematurity & $694(80 \%)$ & $72(64 \%)$ & $<0.001$ \\
SGA & $137(17 \%)$ & $14(13 \%)$ & 0.233 \\
Death & $130(16 \%)$ & $19(17 \%)$ & 0.814
\end{tabular}

No significant differences in diagnoses of prematurity or SGA, or death at discharge were found between NEC-cases in the case-control cohort and cases manually identified for the incidence studies.

Comparison of NEC cases in the case-control cohort and manually identified cases Diagnosis of...

Case-control, $\mathrm{N}=720$ Manually identified, $\mathrm{N}=200$

High grade prematurity

Other prematurity

Any degree of prematurity

SGA

Death $\frac{\mathrm{n}(\%)}{312(43 \%)}$

$328(46 \%)$

$570(79 \%)$

$127(18 \%)$

$111(15 \%)$

$\begin{array}{cc}\mathrm{n}(\%) & \mathrm{p} \\ 78(39 \%) & 0.273 \\ 82(41 \%) & 0.252 \\ 151(76 \%) & 0.265 \\ 175(12 \%) & 0.057 \\ 38(19 \%) & 0.224\end{array}$


Individuals in the case-control cohort without traceable registrations in the NPR

445 individuals in the case-control population, 78 cases and 367 controls, lack information about hospitalisations in the NPR, corresponding to $11 \%$ of cases and $10 \%$ of controls, $\mathrm{p}=0.519$. Controls were evenly distributed over time, annual IRR $0,99(0,97-1,00), p=0.136$, but for cases, there was a positive trend over time with, annual IRR 1.04 (1.01-1.07), $\mathrm{p}=0.020$. Mean gestational age was significantly lower in cases without NPR registrations, 197 (191-203) days, than in cases with posts in the NPR, 219 (216-222) days, as well as in controls, 219 (215-224) and 223 (222-224) days respectively. The strongest factor for infants to lack registrations in the NPR, however, was in hospital death.

Diagnosis of...

High grade prematurity Other prematurity Any degree of prematurity SGA

Death

\section{Comparison of NEC cases in the case-control cohort and manually identified cases}

Cases with/without NPR posts;

\begin{tabular}{ccr|ccr}
\multicolumn{3}{c|}{ Cases with/without NPR posts; } & \multicolumn{3}{c}{ Controls with/without NPR posts; } \\
& $\mathrm{N}=720$ & & \multicolumn{3}{c}{$\mathrm{N}=3656$} \\
\hline With & Without & & With & Without \\
$\mathrm{N}=642$ & $\mathrm{~N}=78$ & & $\mathrm{~N}=3289$ & $\mathrm{~N}=367$ & \\
\hline $\mathrm{n}(\%)$ & $\mathrm{n}(\%)$ & $\mathrm{p}$ & $\mathrm{n}(\%)$ & $\mathrm{n}(\%)$ & \multicolumn{1}{c}{$\mathrm{p}$} \\
\hline $229(36 \%)$ & $48(62 \%)$ & $<0.001$ & $871(26 \%)$ & $109(30 \%)$ & 0.187 \\
$247(38 \%)$ & $20(26 \%)$ & 0.027 & $1530(47 \%)$ & $68(19 \%)$ & $<0.001$ \\
$445(69 \%)$ & $66(85 \%)$ & 0.005 & $2265(69 \%)$ & $172(47 \%)$ & $<0.001$ \\
$154(24 \%)$ & $22(28 \%)$ & 0.413 & $538(15 \%)$ & $58(16 \%)$ & 0.785 \\
$100(16 \%)$ & $75(96 \%)$ & $<0.001$ & $152(5 \%)$ & $217(59 \%)$ & $<0.001$
\end{tabular}




\section{The role of Imaging in the Management of NEC (paper V)}

202 respondents from various countries answered the questionnaire. The distribution between specialties and countries is described in the methods section, table 7 . In the following, the degree of consensus is roughly estimated to be great at around $90 \%$ agreement between respondents and great diversity thought to be present at around $65 \%$ or less, but the assessment is also influenced by the distribution between vague response alternatives such as "sometimes" and more definite ones like "always". Late complications were not addressed. For detailed results and percentages, see paper V.

* There was great consensus on...

...the usefulness of imaging for confirmation of the NEC diagnosis, guidance in the decision on surgery, and surveillance, although there was some diversity of opinions on the invariable use of imaging for these purposes.

...the importance of the clinical picture, the radiographic findings, and the degree of prematurity in the differential diagnosis.

...paralytic ileus and spontaneous intestinal perforation (SIP) as relevant differential diagnoses.

...abdominal radiography (AR) as first choice modality for imaging.

...pneumoperitoneum (PP), pneumatosis intestinalis (PI), and portal venous gas (PVG) as important signs of NEC on AR.

...pneumoperitoneum on $\mathrm{AR}$ as a strong indication for surgery.

- There was moderate agreement on...

...the use of classifications of NEC.

...the importance of age at onset, laboratory findings, ultrasonographic findings, and feed volumes for the differential diagnosis.

...gastrointestinal malformation, obstructive ileus, and Hirschsprung's disease as differential diagnoses.

...the usefulness and availability of ultrasound (US) and the suitability of increasing its use, although almost $90 \%$ thought that it would at least sometimes be useful.

...the importance of a persistent intestinal loop on sequential radiographs as a diagnostic sign or indication for surgery.

...complex (focal or turbid) intraabdominal fluid on US as an indication for surgery. 
There was lack of agreement on...

...imaging as an adjunct in the decision to resume feeding.

...viral enteritis/gastroenteritis and cow's milk protein allergy as relevant differential diagnoses of NEC.

...the importance of gas distribution patterns, intestinal dilatation and separation of intestinal loops as diagnostic signs on AR,

...PVG - if on AR or on US - as a possible indication for surgery.

...PP on US as a strong indication for surgery.

...the perceptions of US being time consuming or disturbing for the infant.

There was also great variation in the routines of imaging in terms of examination frequency, the use of fixed schedules for imaging intervals, and the use of AR with horizontal beam, as well as in the use of US for NEC.

* The use of ultrasound

$58 \%$ of all respondents worked in hospitals where US was used for NEC.

The signs most commonly evaluated were the occurrence of turbid or echoic intraabdominal fluid, PVG, and thickening of the intestinal wall.

This group of respondents agreed to a high extent on the use of US in suspected perforation with inconclusive AR.

There was moderate agreement on the use of US in mild cases with inconclusive $\mathrm{AR}$, and on the evaluation of PI, clear intraabdominal fluid, PP, and intestinal motility with ultrasound.

There was less agreement, around $60 \%$ of respondents from involved centres, on using US in any child with suspected NEC, as first choice modality, or for monitoring known NEC. Lack of consensus was also noted for the evaluation of bowel thinning with US and assessment of bowel perfusion and mesenteric circulation with doppler. 
* Differences between subgroups

Imaging for confirmation of the NEC diagnosis was perceived more important by clinicians than by radiologists. Clinicians used some kind of classification of NEC, e.g. Bell's criteria, Gordon's classification or an informal clinical assessment of suspected-, definite medical- or surgical NEC, more often than radiologists. Radiologists rejected the finding of a persistent loop on sequential radiographs as a possible indication for surgery more often than surgeons. Complex intraabdominal fluid as a possible indication for surgery, on the other hand, was rejected by more surgeons than radiologists but accepted more often where US was used for NEC than where it was not.

Clinicians reported that they read abdominal radiographs by themselves to a greater extent than radiologists thought they did. Radiologists reported more influence on the choice of modality than clinicians thought they had. Further analysis showed one difference within radiology, American radiologists reporting less influence on the decision than other radiologists, and another between specialties outside America.

US was thought to be useful (response alternative "yes") by 65\% (56-73\%) of respondents from hospitals where US was used for NEC compared to 25\% (17$36 \%)$ from hospitals where it was not, and should be used more according to $59 \%(50-68 \%)$ and $31 \%(22-42 \%)$ respectively.

Clinicians, doing US themselves or not, thought to a lesser extent than radiologists that ultrasound was time consuming. It was perceived readily available significantly more often by clinicians from hospitals, where clinicians do US, than where it is done for NEC but not by clinicians, the alternative "yes" indicated by $71 \%(52-84 \%)$ and $36 \%(22-52 \%)$ respectively.

Clinicians showed a more positive attitude than radiologists to the idea of clinicians learning to do US. As for screening for PVG, $8 \%$ of all were positive, without significant differences between specialties, but only $8 \%(4-17 \%)$ of radiologists thought clinicians should learn to do a full abdominal ultrasound, to be compared to $54 \%$ (45-62\%) of all clinicians and $82 \%$ (65-92\%) of clinicians from hospitals where clinicians do US in NEC. Of all 74 radiologists, however, only three worked in such hospitals. 


\section{Discussion}

\section{Incidence and mortality}

The epidemiology of necrotising enterocolitis (NEC) in Sweden 1987-2009, compared to other study populations, was characterised by a low over-all incidence, low proportion of surgical treatment and low mortality. The latter two may partly be explained by the inclusive case definition of NEC in our studies, using the ICD diagnose codes without differentiation between suspected and verified cases. Population based epidemiological studies including all stages of NEC and all gestational ages and birthweights are rare. Holman et.al, also using discharge diagnose codes, described an overall NEC incidence of 1.1 in 1,000 live births in the US in the year 2000, which is almost twice the Swedish incidence rate during the last sub-period, 2005-2009. They reported $27 \%$ surgical treatment and a case mortality rate of $15 \%,{ }^{140}$ which corresponds well to our findings of $24 \%$ early surgery and 15\% NEC related mortality. Rees et.al also included Bell stage I-III in their survey of NEC in the UK during two winter months in 2005 and two summer months in 2006.202 Their reported incidence of $2 \%$ is, however, based on 10,946 admissions to neonatal units, rather than on live births in the population. The cross sectional nature of their study disconnects reported incidence, frequency of surgical interventions and NEC related mortality on the level of individuals, impairing direct comparison to our population based results, but mortality with NEC in their study population seems to be in parity with our finding. ${ }^{202} \mathrm{~A}$ bit surprising, we found no difference in mortality between surgically treated and medically managed NEC cases, but mortality was considerably higher in lower gestational ages, with birthweight as the decisive factor.

Other population based studies are restricted to certain groups of gestational ages and/or birthweights. From the Vermont-Oxford Network, Hull et.al. reported 9\% NEC, defined according to the VON criteria, in 188,703 infants with birth weights 401-1500 g during 2006-2010. ${ }^{200}$ Youn et.al. reported 6.4\% NEC stage II or more according to Bell's criteria in very low birthweight (VLBW) infants $(<1500 \mathrm{~g})$ in South Korea in 2013-2014. ${ }^{147}$ Despite a more inclusive case definition, the average incidence in the corresponding subgroups of our population was only $2.7 \% .{ }^{91}$ 


\section{Variations over time and between populations}

The main result of paper I was an increasing incidence of NEC over time in all subgroups, so that the incidence rate towards the end of the study period approached that of other populations. ${ }^{91}$ The results of others have been contradictory in this respect. $25,83,90,98,218-220$ Some claim that the incidence is probably unchanged, and that variations depend on the confusion over how to define NEC, ${ }^{198,203,221}$ which, with its multifactorial aetiology, is rather the common result of several pathophysiological pathways than one disease entity. ${ }^{18}$

Apart from discrepancies in case definition and the inclusion or exclusion of mild cases, possible explanations for variations of NEC incidence within and between populations may be differences in the composition of populations in terms of gestational ages, distribution of risk factors, protective factors, and comorbidities, as well as clinical practices.

Increased survival of infants at risk of developing NEC apparently contributes on a population level. The proportion of term infants in the Swedish NEC cohort was comparatively high, but decreased towards the end of the study period. This development reflects a relatively low initial frequency of premature births in Sweden, followed by an increasing proportion of premature infants in the general population and an earlier and more rapid rise in NEC incidence rates in the premature groups compared to later gestational ages.

Heida et.al. found increasing incidence rates of NEC in the most preterm and low birthweight infants in three centres in the Netherlands, when guidelines changed towards active treatment at lower gestational ages. ${ }^{222}$ In contrast to our results, no increase was seen in the term, near term or normal birthweight groups, and the proportion having surgery diminished. The latter is opposed to the observation by Snyder et.al. that very low birth weight (VLBW) infants are more likely to require surgery than non-VLBW. Stoll et.al. reported an increasing trend among gestational ages 22-28 w for the years 1993-2008 but a decreasing trend 2009-2012. The dynamic suggested by Holman et.al. ${ }^{83}$ with advances in neonatal care, causing an initial reduction in NEC incidence followed by an increase as the early survival in the population at risk improved, may eventually transition to a phase of stabilised or even decreasing incidence, when some of the prophylactic measures learned along the way gain effect. 


\section{Seasonal variation and clustering}

There are many reports on outbreaks, sometimes termed clusters, and epidemics of NEC and, as Gordon et.al. put it, "there is almost no known neonatal pathogen ... that has not been associated with NEC." 12 Nevertheless, previous evidence on the occurrence of clustering and seasonal variation on a population level is scarce. A few others report on seasonal variation, although with slightly different months for peaks and troughs. We found a peak in November and a trough in May, in Snyder's study from the US 1992-2005 the peak was in December and the trough in June, ${ }^{105}$ and Lu et.al. reported January and August respectively in China 2010-2015.106 The common denominator is a cyclicity with about half a year between the higher incidence in winter and the lower incidence in summer. This could correspond to viral infection as a precipitating cause in a sufficient number of NEC cases to result in a measurable seasonal variation. Gordon et.al. suggested in 2007 that what occurs with seasonal variation and in clusters would not be NEC but viral enteritis of infancy, ${ }^{9}$ which is a matter of definition. In a more recent article, a couple of the same authors suggested that microbial contagions may rather act as triggers for the pathophysiological pathway, leading to one of the subsets of NEC. ${ }^{12}$ The distinction may be important in defining future study populations, but clinically the difference is hard to tell and probably has little influence on management, although prognosis may differ. Among neonatologists and paediatric surgeons responding to the questionnaire described in paper $\mathrm{V}$, viral enteritis was not regularly considered among the differential diagnoses of NEC.

In our population, as shown in paper II, space-time clustering was seen, when delivery hospital was used to define space, but could not be associated with the residential municipality of the mother, suggesting a contagious precipitating cause in the hospital environment. Knox space-time analysis showed a greater occurrence of pairs of NEC cases, appearing close in space and time, than expected from merely sporadic cases during the first part of the study period, but not enough to reach statistical significance during the second one. This may reflect improved hygiene or some other change of routines in neonatal intensive care units. According to the Kulldorff's space-time permutation scan, however, significant clustering did not disappear during the second part of the study period. ${ }^{223}$ The disconnect between an increase of overall NEC incidence and the 
signs suggesting a diminishing influence of one possible precipitating cause, once again illustrates the multifactorial nature of the disease and contradicts any suspicion that the increase in NEC incidence would be due to increasing misclassification of viral enteritis as NEC.

\section{Risk factors}

The epidemiological literature on NEC is no longer scarce, but still very heterogenous. The immaturity of the neonate, expressed as low gestational age and low birthweight, is the most consistent risk factor. Apart from that, a great number of observational studies have suggested other predisposing, precipitating, and co-variating factors, often varying between populations and subgroups, depending on the selection of gestational ages and birthweights. Many of them are restricted to one or a few institutions, certain gestational ages, or a limited number of risk factors. Out of a total of 43 statistically significant risk factors identified by 14 prognostic studies on NEC included in a recent systematic review, only eleven were identified by more than one study. ${ }^{224} \mathrm{We}$ analysed an extensive number of potential risk factors in cases and matched controls of all gestational ages, although stratified to correct for potential differences in pathogenesis between sub-groups. Since temporal relationships cannot be discerned, and clinical information such as feeding and medication is missing altogether, detected associations need to be interpreted with care.

Like in many previous studies, risk factors in our population, as described in paper III, were more obvious in the more mature groups than in lower gestational ages. One possible explanation is differences in pathophysiological pathways depending on the maturity of the individual in accordance with the perception that NEC is not one disease entity but many. ${ }^{12,18} \mathrm{~A}$ simpler assumption would be that risk factors in mature individuals do not show in lower gestational ages, because the vulnerable immature neonates do not survive them. One apparent reflection of this is the early survival among NEC cases compared to controls in the most immature subgroup. Some controls, dying within one week of birth, probably would have developed NEC if they had survived. This may be true also for vulnerable individuals in higher gestational ages, explaining why increased early survival seems to lead to increased NEC incidence in all gestational ages, as shown in paper I. ${ }^{91}$ In this context, although not shown in our study, it is interesting to note that congenital 
cardiac heart disease, usually regarded as a risk factor confined to term and near-term infants, has been identified as risk factors also in VLBW infants. 87,145 This does not contradict that the pathophysiology differs between the most common NEC subset in highly premature infants and the subset presumably precipitated by disturbed mesenteric perfusion from congenital heart disease and asphyxic events in term and near-term infants. It only underlines the complexity of the disease and suggests that the overlap between subsets of NEC may increase with increasing survival of vulnerable neonates of all gestational ages. The latter may be supported by the occurrence of early onset NEC, previously regarded as a characteristic of NEC in term infants, ${ }^{9}$ also among infants of low gestational ages. ${ }^{27}$

Among the results in paper III, the negative associations with maternal urinary infection and premature rupture of the membranes (PROM), are somewhat surprising, especially as PROM, leading to chorioamnionitis, has been suggested as a risk factor of NEC by several investigators, including one metaanalysis, ${ }^{131-134}$ but contradicted by others. ${ }^{225,226}$ Infected amniotic fluid, e.g. in chorioamnionitis or prolonged rupture of membranes, is also believed to play a role in the "two-hit hypothesis". ${ }^{19}$ Sharma et.al. reported two cases of NEC with portal venous gas in unfed infants born to mothers with chorioamnionitis, and suggested that ingestion of infected amniotic fluid might have been the cause. ${ }^{23}$ We found no association with a diagnosis of chorioamnionitis.

Our findings could be dismissed as statistical artefacts, assuming that, since urinary infection and premature rupture of the membranes are both associated with pre-term birth, and therefore common among controls, the cause of prematurity in infants susceptible to NEC would be some other pregnancy related factor not investigated in this study. On the other hand, there are a couple of conceivable mechanisms that may contribute to a protective effect. Cytokine and immunoglobulin content of maternal milk may be affected by the microbial environment of the pregnant mother. ${ }^{185,227,228}$ Immunoglobulins are transported over the placenta, beginning as early as gestational week 13 , even if the greatest amounts are transferred during the third trimester. ${ }^{16,228} \mathrm{We}$ speculate that low grade antenatal exposure to bacteria, possibly balanced by a short course of antibiotics, may speed up this process. A meta-analysis from 2013 of treatment of mothers for premature rupture of membranes, found a 
tendency towards lower risk for NEC with a shorter course of antibiotics. ${ }^{124}$ The difference between study populations, and wether the exposure to premature rupture of the membranes or maternal urinary infection promotes or prevents NEC could possibly be influenced by how it is handled clinically, alternatively by the presence or absence of some contributing risk factor tipping the balance of the cross-talk between host defence and microbiota in the direction of exaggerated inflammatory response.

A theoretical connection can be made to the positive association caesarean section (CS) with NEC except in GA<28 w, even though there is an obvious risk of selection bias in higher gestational ages, with some antenatal or perinatal problem, not included in the statistical model, predisposing for NEC rather than the delivery mode itself. Earlier results on the impact of delivery mode on the risk for NEC have been mainly inconclusive. ${ }^{27,29,86,139}$

CS is associated with higher incidence of respiratory problems at birth, 229,230 which is generally thought to be caused by the by-stepping of the normal physiological adaptations to postnatal life triggered by vaginal delivery. It is plausible that this could influence intestinal maturation as well, which, to my knowledge, has not been studied. Probably more important, lower diversity of the gut microbiota of the new-born and differences in dominant species have been demonstrated after CS compared to infants born by the vaginal route. ${ }^{231,232}$ These alterations may predispose to NEC. ${ }^{222,232,233}$ In vaginal delivery, colonisation of the infant gut is expected to result from the direct exposure to maternal vaginal and intestinal flora, but it was also found in a small study, that the composition of the microbiome in breast milk differed after elective CS compared to normal labour, ${ }^{234}$ indicating a complementary mechanism for colonisation. Moreover, CS has been shown to have a negative impact on breast feeding, ${ }^{229,235}$ which could theoretically also contribute to the risk of NEC in term and near-term infants.

In contrast to cardiac malformations, which in this population, like in many other studies, ${ }^{93,112,115,149}$ was associated with NEC in term and near-term infants only, the association with persistent ductus arteriosus (PDA) was positive in all sub-groups, albeit statistically significant only for term and moderately premature infants. Unlike some earlier reports, ${ }^{167,236}$ surgical treatment did not further enhance the association, but whether the patent ductus itself, treatment 
with indomethacin, or perhaps a combination of both, accounted for the enhanced risk is not possible to discern. A hemodynamically significant PDA results in reduced blood flow to the mesenteric vascular bed and so does medical treatment with indomethacin. ${ }^{146}$ Both have been suggested as risk factors of NEC in earlier studies. ${ }^{82,237}$

Our data do not reveal whether the association of NEC with isoimmunisation is linked with the condition itself or with its treatment. Case reports and retrospective studies have suggested that treatment of hemolytic anemia with intravenous immunoglobulins may precipitate NEC,156,158 which is also counted among complications of exchange transfusion ${ }^{106,238}$ but Roig and Burchfield reported two cases of NEC in infants with isoimmunisation before exchange transfusion. ${ }^{239}$ Isoimmunisation is likely to predispose to general vulnerability and can be speculated to contribute to imbalance of the developing immune system, which might precipitate NEC.

Other associations that escape interpretation are red cell transfusion and bacterial infection including sepsis, where the temporal relationships with the onset of NEC are unknown.

Evidence on the role of transfusion is equivocal. ${ }^{240}$ It may rather mirror the general vulnerable state of infants susceptible to NEC or, as Hay et.al. suggest, even treatment given for prodromal symptoms of $\mathrm{NEC}^{240}$ or for sepsis secondary to NEC. There could, however, be a subset of infants, where red blood cell transfusions, possibly in connection with feeding, do induce great fluctuations in oxygen saturation in the splanchnic circulation, causing intestinal injury which precipitates NEC, as investigated in a very small study in VLBW infants examined with near infrared spectroscopy (NIRS).

The suggested mechanism for transfusion induced intestinal injury through immunologic influence on the mesenteric arterial reactivity and nitric oxide pathways, ${ }^{173}$ maybe could also be at work in isoimmunisation, immunoglobulin treatment and/or exchange transfusion. It would be interesting to see larger, clinical studies using NIRS in this context.

Sepsis is a well-known manifestation of NEC, but has also been suggested as a contributing factor in the pathogenesis. ${ }^{21,88,112}$ Without information on the temporal relationships of the diagnoses, the interpretation of our finding is unclear. 
The most likely explanation of the negative association of NEC with neonatal icterus, despite a positive association with isoimmunisation, is that uncomplicated neonatal icterus is very common, whereas icterus caused by e.g. isoimmunisation and haemolysis does not result in an additional diagnosis.

\section{Intestinal failure}

$6 \%$ of NEC cases developed intestinal failure (IF), compared to $0.4 \%$ of controls. Apart from a history of NEC, abdominal surgery and a later birth year were the only predictors of IF. Neither in NEC cases, nor in controls does lower gestational age or birthweight emerge as a risk factor for IF. This is probably explained by the small numbers and, in controls, the matched case-control study design.

The positive trend for IF over time is apparently due to a significant rise in IF incidence rates during the last sub-period compared to the first one. One suggested cause is increased survival of individuals with more serious NEC, although the increase is seen in controls as well and there was no decrease of mortality in NEC cases during the study period. An increasing occurrence of abdominal surgery early in life may also have an influence, at least in cases, where a weak but significant trend was seen over time. Finally, the possibility of registration bias must be considered. During the first two sub-periods, none of the IF cases has a registration of total parental nutrition, but during the third sub-period, 6 out of 18 received TPN, according to the patient register, and during the last 30 out of 35 . Counting only those with a discharge diagnosis of postoperative or non-specified intestinal malabsorption, there was however still a significant difference between the first two sub-periods on the one hand, and the last two on the other. Using only diagnose codes, and adjusting for sex, gestational age, birthweight, NEC, and early surgery there was still a positive trend over time with an overall annual IRR of 1.10 (1.03-1.18), $\mathrm{p}=0.007$ and no significant difference between cases and controls. A strong, positive association with early, abdominal surgery remained in this model.

The comparatively low frequency of IF in our NEC cohort may be influenced by the use of discharge codes for identification of NEC cases including not only both medical and surgical NEC but possibly also suspected cases. On the other hand, the $3 \%$ among medically treated cases is in parity with previously reported rates. ${ }^{216}$ It is the proportion of IF in surgically treated patients that is 
low. ${ }^{215,216}$ A possible explanation is that some of the operated patients may have had SIP and not NEC, which may lower the risk of IF. Kelleher et.al., also including both diagnoses, found $12-14 \%$ IF among patients after laparotomy for NEC or intestinal perforation. ${ }^{209}$ Excluding those with double diagnoses in our study population, however, only increased the rate of IF from 14 to $15 \%$ of NEC patients after early surgery. 5 patients with a discharge code of SIP also had codes indicative of IF. A few cases of IF might be lost because of the exclusion of hospitalisations with procedural codes defining IF starting less than 2 weeks after birth, but there were only two such hospitalisations, one belonging to a NEC case, and one to a control. Except for uncertainties in the definition of IF and lack of relevant diagnose codes, which may lead to cases of IF not being reported to the register at all, the reasons for this relatively low incidence of IF in surgically treated NEC is unclear.

The conclusions that can be made are thus limited, but, apart from confirming NEC as a strong risk factor for IF, our results show that IF does occur after premature birth also without a history of NEC. Given the increased incidence of IF in the last years of the study period, there should be prospects of future studies, preferably with clear definitions and a prospective design, to characterise the risk factors and consequences of IF, so that the increasing trend can be turned around.

\section{Strengths and limitations of the register studies}

The comprehensive health care databases held by the Swedish National Board of Health and Welfare offer good opportunities for epidemiological research. Despite a small population and, from an international perspective, low incidence rates of NEC in Sweden, the study population, on which papers I-IV are based, represents a large number of subjects over a period of 23 years, in which major advances have been made in ante- and perinatal care, including the transition from the pre-surfactant to the surfactant era and new national guidelines on centralisation of neonatal services and individualised management of the extremely premature. As a result, a significant growth of the population at greatest risk for NEC has occurred.

On evaluation, the registers used have been found to hold high quality. Nevertheless, as is the case in all register studies, the data were routinely collected for administrative reasons rather than specifically for research, which 
implies that the information collected cannot be adapted to the objective of the studies, but the study design and research questions must be conformed with the available information. The definition of a case being the presence of a discharge diagnosis, diagnostic criteria for NEC in each case are unknown. This should be kept in mind when interpreting the results, especially when comparing them to the results of others.

The issues with defining NEC cases is, however, not only a problem when using discharge data. What criteria to use and how to subclassify this multifactorial condition and avoid "contamination" of datasets, is an ongoing discussion. ${ }^{12}$ In this study population, there were 64 cases and 14 controls with a diagnosis of spontaneous intestinal perforation (SIP).

The occurrence of SIP among cases may reflect an increasing awareness of this diagnosis, without separating it from NEC, revised diagnoses after surgery for presumed NEC, misclassification of perforated NEC, or even the development of NEC after surgical recovery from SIP, which may occasionally occur. ${ }^{12}$ The decision to keep NEC cases, who also were diagnosed with SIP, was supported by the fact that the mortality among cases with a SIP diagnosis was higher than among those without one. Since SIP is supposed to be a more benign condition than perforated NEC, ${ }^{241}$ this would indicate that SIP represents the misclassification. According to a recent report, however, this may not be an undisputable truth. ${ }^{35}$ Nevertheless, the awareness of SIP and its distinction from NEC can be assumed to have increased over time, so that the occurrence of SIP is more overt towards the end of the study period, without really having increased, which would lead to bias, if NEC cases with double diagnoses of SIP and NEC were to be excluded.

Missing personal identification numbers in new-born infants is another problem in using the registers. The number is given to all Swedish residents at birth or immigration, ${ }^{242}$ but during the study period, there was a delay of a few weeks before new-borns received their number, resulting in a substantial proportion of discharge registrations with missing identification number, impeding linkage between individual hospitalisations belonging to one individual as well as between registers. Attempts to compensate for this problem, were the manual identification of NEC patients from data in the PTR and MBR for the incidence studies (paper I and II) and the including of 
procedural codes describing stoma reversal to identify individuals, whose primary surgery was registered with a hospitalisation lacking identity information. When comparing diagnoses of prematurity, occurrence of abdominal surgery, mortality, and sex distribution between subjects and hospitalisations with complete and incomplete identification, the datasets used for the studies were perceived as representative, and the risk of bias sufficiently reduced through the matched case-control design. The lack of eligible matched controls unfortunately reduced the size of the control group and introduced an asymmetrical distribution of cases and controls in the lowest gestational ages. Apart from issues with power, this should not bias the results, since the matching variables were included in all regressions.

It is well known that NEC is a very complex, multifactorial and heterogenous disease entity with different pathophysiological pathways and subpopulations, presumably with some risk factors in common and some that differ. Many studies are limited to certain gestational ages, birthweights, or specific risk factors. We investigated the entire Swedish NEC cohorts of 23 years and analysed a great number of potential risk factors. Doing so, the risk of overfitting the statistical model is obvious, and the results need to be interpreted in the context of previous studies and current pathophysiological knowledge. At the same time, findings contrasting to the results of others may give rise to the most interesting reflections and, at its best, to further research impulses.

\section{Classifications}

Register studies and imaging meet at the level of case definitions. Bohnhorst et.al suggested a classification system should provide a proper definition of the disease, help to make an early diagnosis, help decisions on treatment, e.g. clarifying indications for surgery, and create a reference standard for scientific studies. $^{34}$

There is, however, some confusion over classification systems and their use for case definition, staging or subdivision. The so called "Bell's criteria" were initially intended as a staging system to guide clinical decisions in patients with $\mathrm{NEC}, 7,8$ and not designed as a reference standard for scientific studies, although frequently used as such. In contrast, "Gordon's classification", ${ }^{34,243}$ is originally rather a system for differential diagnosis of NEC against SIP and other acquired neonatal intestinal diseases (ANIDs), ${ }^{9}$ which has evolved into a classification 
system, still excluding SIP but else aiming, not so much at narrowing the definition of NEC, as at dividing it into subgroups, focusing on aetiology and susceptible sub-populations. ${ }^{12,30}$ The latter may pose a problem where aetiology is multifactorial and sometimes unknown, and the windows of susceptibility change with changing characteristics of the population at risk.

Imaging, especially abdominal radiography (AR), is an integrated part in the definition as well as the management of NEC. Corresponding to the multifactorial nature of the disease, however, there is a broad spectrum, not only of clinical presentations, but also of radiographic signs, and not even intramural gas/pneumatosis intestinalis, traditionally regarded pathognomonic for NEC, is consistently or exclusively found in NEC. ${ }^{9,22}$

The respondents in our survey, described in paper $\mathrm{V}$, largely preferred a clinical assessment of "suspected", "definite medical" or "surgical" NEC to formal Bell's staging system or Gordon's classification. The "VON Criteria", 200,208 used to define NEC in the Vermont-Oxford Network, were unknown to us at the time the questionnaires were constructed, and, probably due to the lack of North American clinicians among the respondents, it was not mentioned in free text by any of the respondents.

The propensity score, lately proposed by Battersby et.al., ${ }^{244}$ is designed to decide whether NEC, regardless of severity, is present or not. It is attractive in being somewhat less dependent on radiographic signs than other diagnostic classifications, but illustrates several of the problems in accurately defining a case of verified NEC and evaluating diagnostic criteria in the absence of an independent reference standard other than surgical or post-mortem findings.

\section{The role of imaging in the management of NEC}

In their conclusion from 1978 Daneman et.al pointed out that the radiologist might be the first to suspect the diagnosis of NEC and the first to predict or detect its complications. ${ }^{22}$ Since then the awareness of NEC has increased, and the question is rarely missing when a neonate is referred for AR.

It is well known that patients with suspected NEC are often treated as having NEC, even if the diagnosis is not supported by imaging, and may as well be operated on, if their clinical state is severe enough. $23,31,46,73,245$ Among our respondents, the clinical picture was also almost unanimously regarded as the most important aspect in differential diagnosis, closely followed, however, by 
radiographic findings. The importance of interpreting the radiographic findings in the light of the clinical situation, as pointed out by Kogutt in 1979,41 was stressed in multiple free text answers to the concluding question about the role of imaging - what it is and what it should be.

Once the diagnosis is suspected, the priority in clinical practice, unlike research, seems to be to distinguish NEC in need of surgery from less serious NEC and NEC-like conditions.

Apart from the interpretation of the subtler signs on AR, and the importance of some clinical aspects, such as degree of prematurity, gestational age and feed volumes, for differential diagnosis, the areas in need of clarification, as they appeared in the survey, were mainly related to imaging routines, the use of ultrasound, and indications for surgery.

Imaging routines

Imaging routines varied in terms of examination frequency, the use of fixed schedules for imaging intervals, and the use of AR with horizontal beam, much in keeping with the results from a survey on NEC management by Zani et.al..32 Since we did not ask for the examination frequency of AR and ultrasound (US) specifically, any influence of the use of US on the frequency of AR, and thereby the exposure to ionising radiation, could not be assessed.

The early recommendation of AR every $6^{\text {th }}$ hour ${ }^{46}$ was motivated by the fact that radiographic signs may precede clinical deterioration, and a high examination frequency aimed at avoiding delay of adequate treatment. The introduction of new methods for monitoring, such as biomarkers and NIRS, ${ }^{203,205}$ may influence the role of imaging in this context.

Studies designed to evaluate outcome and complication rates with different protocols for examination frequency and choice of modality would be valuable, ideally with the goal to develop guidelines to support decision making based on individual assessment, rather than fixed algorithms. 
Ultrasound

$75 \%$ of clinicians would attribute at least some importance to ultrasonographic findings in differential diagnosis, which was a greater proportion than had access to US for NEC. On the other hand, as many as $22 \%$ stated that such findings would be of no importance at all.

Almost $60 \%$ of survey respondents worked at hospitals where ultrasound was used for NEC, and some of the others expressed that they would like it to be used more. It is, however, rarely used as the first-choice modality or as a part of the routine work-up, as suggested in $1994^{46}$ but rather for gathering more information when AR is inconclusive, i.e., as stated by Silva et.al, "a problemsolving modality only in those neonates suspected or known to have NEC and in whom it is thought that more information provided by [abdominal US] might facilitate management decisions". ${ }^{39}$ It seems infrequently used for monitoring NEC, but there are studies suggesting that some ultrasonographic signs are highly sensitive for the need of surgical intervention. ${ }^{39,42,53,59,68}$

Although most survey respondents thought that US would, at least sometimes, be useful, the often repeated objections of availability and operator dependency $^{211}$ were expressed, as were concerns about the validity of ultrasonographic findings. Both may possibly be overcome by systematic examination protocols and saving of pictures and cine-loops for re-evaluation by experienced radiologists. Almost half of the respondents from departments where clinicians do ultrasound had such support. The problem with "operator dependency" in NEC imaging does however not only apply to US. Mata and Rosengart go so far as to suggest that the reported variation in NEC incidence may be attributed to interobserver variability in AR. ${ }^{48}$

With $\mathrm{AR}$ as an integrated part of current classifications and diagnostic criteria for NEC, it is obvious that studies to validate US as a potentially more sensitive modality are difficult to design. ${ }^{24}$ The same problem applies to AR itself, which, however, is more established in the clinical tradition. For both modalities, available studies are heterogenous in design, selection of evaluated signs, and reference standards, impairing comparison and conclusive interpretation of results.

As shown in table 4 of paper V, ultrasonographic signs used by over $90 \%$ of survey respondents acquainted with US for NEC were focal and turbid fluid, 
portal venous gas (PVG), and bowel thickening, followed by pneumatosis intestinalis (PI) and clear fluid at $86 \%$ each, all of which have been well studied, some for early diagnosis, others for detection of complications. PVG is the most extensively studied ultrasonographic sign, reported on in 14 out of 20 studies published 1984-2016, followed by PI and turbid fluid, reported on by 10 and 9 studies respectively, see table 5 in the Background section. Concluding a review article, including most of those studies, Bohnhorst recommended US for early detection of PVG, evaluation of fluid in the abdominal cavity, and assessment of bowel wall perfusion, ${ }^{52}$ of which bowel wall perfusion seems less commonly used than the others.

Silva et.al. suggested that US and AR evaluate different manifestations of underlying pathology. ${ }^{72}$ Therefore the question for future studies should not be which modality to choose for NEC imaging but how to use them together, possibly involving clinical aspects, other diagnostic methods and presumptive classification systems as well.

\section{Indications for surgery}

The decision to operate is an act of balance between early intervention, when needed, and avoidance of unnecessary surgery, ideally timed when intestinal necrosis is demarcated but prior to perforation and/or progressive physiologic derangement. ${ }^{203}$ Pneumoperitoneum (PP) on AR is often stated to be an "absolute indication" for surgery, 70,202 but only $88 \%$ of our survey respondents, stated that it would "always" prompt surgical intervention. More problematic, it is known to be missing in a great proportion of infants with perforated NEC. $31,75,37$ The distribution of opinions on persistent loop on sequential radiographs and portal venous gas on $A R$ as indications for surgery is similar to the equivocal results in the literature. ${ }^{23,56-59,79,199,204}$

Reported results on the potential of US to bridge the lack of sensitivity of AR for intestinal perforation and bowel necrosis are promising. ${ }^{53,68,71,72}$ There is no contradiction between the reports on the ability of some radiographic and ultrasonographic findings, other than PP, to predict the need for surgery ${ }^{59}$ and the effect of timing surgery according to a combination of metabolic parameters (MD7) on outcome. ${ }^{206,246}$ Both may contribute to the improvement of NEC surveillance. 
The spontaneous impression of table 5 of paper V may be that signs on US, suggesting bowel necrosis or perforation, were not taken as seriously as the corresponding signs on AR. The different understanding of PP on US compared to AR may, however, be adequately motivated by the high sensitivity of US for gas artefacts, requiring only a very small and potentially self-sealing perforation to be detected. In that perspective it is rather surprising that PVG on US, once reported as an early sign of NEC, $44,80,54,55$ is regarded a possible indication for surgery as often as PVG on AR. Persistent loop on sequential AR and turbid or localised fluid on ultrasound may partly mirror similar pathology, ${ }^{72}$ and are considered possible indications for surgery by similar proportions of respondents.

\section{Concluding remark}

Progress on the role of imaging in clinical decision making may have been slow, but recent studies, often with a multimodal design, have delivered promising results. The close interaction between involved specialties, called for by some of the respondents to our questionnaire, is needed not only clinically but in designing and implementing effective scientific studies as well.

\section{Strengths and limitations of the survey}

This survey collected a large number of respondents with an even distribution between specialties. Unfortunately, however, the respondents from different specialties were very unevenly distributed geographically. Because of the open invitation to participate, no response rate could be calculated, and there is no guarantee against double responses. Hence, the respondents represent only themselves, and the results must be interpreted as they are: the perceptions and opinions of 202 professionals with an interest in and, presumably, experience of the management of necrotising enterocolitis. The questions were constructed with guidance from literature studies, interviews, and a pilot survey, but no validation was done of the questionnaires. Calculating and describing proportions may be criticised as a quantitative approach to a qualitative question, but with all the mentioned reservations, it gives an idea of which issues need to be clarified, which may serve as a base for further discussion and planning of studies on the optimal use of medical imaging in NEC management. 


\section{Conclusions}

\section{Register studies:}

I. Alongside a dramatically improved early infant survival, especially in extremely preterm and low birthweight infants, the incidence rate of necrotising enterocolitis (NEC) in Sweden increased during the study period 1987-2009. There were no convincing regional differences in NEC incidence, but seasonal variation suggests an influence of environmental factors.

II. The occurrence of space-time clusters, associated with the delivery hospital but not with the residential municipality of the mother, suggests that contagious environmental factors encountered after birth may precipitate NEC. The decrease of clustering over time may indicate that improved routines in neonatal care units have been effective in reducing the transmission of precipitating agents between patients.

III. A complex pattern of associations between NEC and numerous factors related to the mother, the pregnancy, the infant, and perinatal events supports the notion that NEC is a common pathophysiological pathway of multifactorial etiology, rather than a uniform disease entity. Some of the risk factors identified in the study seem to be primarily related to an unspecific vulnerability, others may have more direct pathophysiologic associations with NEC, and some may affect both.

IV. The risk of intestinal failure (IF) was increased sevenfold in NEC cases compared to matched controls, and the incidence was strikingly higher towards the end of the study period. Abdominal surgery, extreme prematurity, and fetal growth restriction seem to contribute to the risk of IF. Further studies are needed to understand the causes of the increasing incidence and how it may be prevented. 
Multispecialist survey

V. Despite great consensus on the purposes of imaging in NEC and the most important radiographic signs of the disease, there is considerable diversity in routines, especially regarding examination frequency and the use of ultrasound. Important objectives for future studies include continuing validation of ultrasound, definition of the supplementary roles of both imaging modalities in relation to other diagnostic parameters, and evaluation of imaging routines in relation to complications and timing of necessary interventions. 


\section{Sammanfattning på svenska}

Nekrotiserande enterokolit, förkortat NEC, är en tarminflammation som drabbar nyfödda, oftast för tidigt födda barn. Samspelet mellan tarmbakterier och det medfödda immunförsvaret spelar en viktig roll i utvecklingen av NEC, men det finns många olika mekanismer och utlösande orsaker till sjukdomen.

Förloppet kan vara lindrigt och lätt att behandla, men det kan också vara mycket allvarligt med blodförgiftning och hög dödlighet. I allvarliga fall krävs att man opererar bort skadad tarm, men det gäller att följa förloppet noga, så att man varken väntar för länge eller opererar i onödan. Bilddiagnostik, såsom röntgen- och ultraljudsundersökningar, spelar därför en viktig roll i omhändertagandet.

I efterförloppet, kan barn som har haft NEC få förträngningar på tarmen eller försämrad förmåga att ta upp näringsämnen, så kallad tarmsvikt. De har också ökad risk att drabbas av utvecklingsförsening och neuropsykiatriska funktionshinder.

I den här avhandlingen har Socialstyrelsens register använts för att beskriva NEC i Sverige under åren 1987-2009.

Under den perioden drabbades i genomsnitt 34 av 100000 levande födda barn av NEC. Andelen var mer än dubbelt så stor under de sista fem åren som under de första sex. Samtidigt överlevde allt fler nyfödda sin första vecka, inte minst bland de mest för tidigt födda som löper störst risk att få NEC. Bland dem som vägde mindre än $750 \mathrm{~g}$ vid födelsen drabbades 100-160 gånger fler än genomsnittet.

Under första delen av studieperioden förekom fler ansamlingar av NEC på förlossningssjukhus än förväntat, om sjukdomsfallen hade inträffat helt slumpmässigt. Det kan ha berott på att något i omgivningen utlöste NEC. Att man inte på samma sätt såg ansamlingar under den senare delen av studieperioden kan tyda på att förbättrade rutiner i vården minskade risken för att smittämnen överfördes till de nyfödda.

När barn som fått NEC jämfördes med barn som var födda samma år och efter samma graviditetslängd, "kontroller", såg man ett komplicerat mönster av samband med olika tänkbara orsaker. Vilka av dessa som verkligen har betydelse för uppkomsten av NEC kan man inte säkert avgöra genom att studera registren, men resultaten kan ligga till grund för framtida forskning. 
En knapp fjärdedel av NEC-patienterna blev opererade under spädbarnstiden. 3 av 20 - nästan dubbelt så många som bland kontrollerna - dog före en månads ålder. Drygt en av 20 fick tarmsvikt i efterförloppet av NEC.

Bilddiagnostikens roll, så som den uppfattas av läkare som arbetar med NEC, undersöktes med en enkät. 202 barnläkare, barnkirurger och röntgenläkare från olika länder svarade. De var överens om betydelsen av röntgen i omhändertagandet av NEC och om hur man ska tolka de viktigaste fynden. Sådant som kan behöva forskas mera omkring, är hur ofta barn med NEC behöver röntgas, hur man bäst använder ultraljud och vilka undersökningsfynd som talar för att man behöver operera.

Nekrotiserande enterokolit är en komplicerad sjukdom som har blivit vanligare i takt med att de allra sköraste spädbarnen överlever. Att förstå vilka faktorer som utlöser NEC och påverkar förloppet, och i vilka situationer kirurgi behövs, är viktigt för att kunna förebygga sjukdomen och minska risken för bestående men. 


\section{Acknowledgements}

I would like to express my gratitude to all who have supported me along the way to the completion of this thesis, especially the following persons.

My main supervisor, Roland Andersson, for guidance through the rugged terrain of register studies, patient and enduring support, and reliable availability.

My supervisors: Peder Drott, for suggesting NEC as my field of research and accompanying me on the way, Örjan Smedby, for encouraging me to start PhD education and guiding me through all the formalities, and Hans Ringertz for providing the perspective of paediatric radiology, enabling my visit at Lucile Packard's Childerns' Hospital, and patiently sorting out unmanageable results with me.

My co-authors: Amanda Magnusson, Anders Elfvin, Tomas Bexelius, and Erika Rubesova for inspiring collaboration and fostering discussions.

Those who guided me through my early scientific attempts: Sven Almer, Tore Lind, Bengt Lindblad, Gerhard Malmfors, Fredrik Lundgren, and Tina Granholm, for inspiration and encouragement.

Pia Säfström, former head of the radiology department at Linköping University Hospital, for accepting the commitment of the employer when I was accepted as a PhD student, and Mathias Axelsson, her successor, for continuing support and signatures.

My colleagues at the radiology department, especially Johan Blomma and Waldemar Czekierda, for enabling me to take time off to finish this work - and Dario Hauer at the cardiology department for letting go of Waldemar all those weeks.

Hugo Stenström, my mentor in radiology and role model. Words superfluous.

Present and former co-workers at Seldingerenheten: for being who you are and accepting me as I am. Together we can do anything. 
My family of origin: my mother, who introduced me at an early age to the fascinating field of medicine, wisely warned me of becoming a physician but always supported my decisions; Elisabeth, my beloved sister, friend, and role model; and, in loving memory, by brother, Björn, and my father, both great sources of inspiration.

Klaus, for your loving companionship - and for putting up with me, feeding me, comforting me, and picking up my samples from print works, depending on what was needed at the moment.

Joel and Markus, centre of my life for so many years, for encouragement, inspiration, and good advice - and many precious memories. Do not be discouraged from research, should the right subject come your way.

Stefan, for your friendship and the history that we share - and for once upon a time making me believe that I could do research. 
1. Sharma R, Hudak M. A Clinical Perspective of Necrotizing Enterocolitis. Past, Present, and Future. Clin Perinatol. 2013;40:27-51.

2. Huda S, Chaudhery S, Ibrahim H, Pramanik A. Neonatal necrotizing enterocolitis: Clinical challenges, pathophysiology and management. Pathophysiology. 2014;21(1):3-12. doi:10.1016/j.pathophys.2013.11.009.

3. Sántulli TV, Schullinger JN, Heird WC, et al. Acute necrotizing enterocolitis in infancy: a review of 64 cases. Pediatrics. 1975;55(3):376-387.

4. Collin JG. Magens Uppmjukning (Gastromalacia). In: Afhandling Om Barns Sjukdomar. Vol II. Norrköping: Chr. Törnequist; 1843:219-227.

5. Kosloske AM. Epidemiology of necrotizing enterocolitis. Acta Paediatr Suppl. 1994;396:2-7.

6. Caplan MS, Fanaroff A. Necrotizing: A historical perspective. Semin Perinatol. 2017;41(1):2-6. doi:10.1053/j.semperi.2016.09.012.

7. Bell M, Ternberg J, Feigin R, al et. Neonatal Enterocolitis: therapeutic decisions based upon clinical staging. Ann Surg. 1978;187:1-7.

8. Walsh MC, Kliegman RM. Necrotizing enterocolitis: treatment based on staging criteria. Pediatr Clin North Am. 1986;33(1):179-201.

9. Gordon PV, Swanson JR, Clark R. Emerging trends in acquired neonatal intestinal disease: is it time to abandon Bell's criteria? J Perinatol. 2007;27(11):661-671. doi:10.1038/sj.jp.7211782.

10. Clark D, Munshi U. Feeding associated neonatal necrotizing enterocolitis (Primary NEC) is an inflammatory bowel disease. Pathophysiology. 2014;21:2934.

11. Torazza R, Li N, Neu J. Decoding the enigma of necrotizing enterocolitis in premature infants. Pathophysiololgy. 2014:21-27.

12. Gordon PV, Swanson JR, MacQueen BC, Christensen RD. A critical question for NEC researchers: Can we create a consensus definition of NEC that facilitates research progress? Semin Perinatol. November 2016. doi:10.1053/j.semperi.2016.09.013.

13. Sharma R, Tepas JJ. Microecology, intestinal epithelial barrier and necrotizing enterocolitis. Pediatr Surg Int. 2010;26(1):11-21. doi:10.1007/s00383-009-2536-2. 
14. Torrazza RM, Ukhanova M, Wang X, et al. Intestinal microbial ecology and environmental factors affecting necrotizing enterocolitis. PloS One. 2013;8(12):e83304. doi:10.1371/journal.pone.0083304.

15. Moore SA, Nighot $P$, Reyes $C$, et al. Intestinal barrier dysfunction in human necrotizing enterocolitis. J Pediatr Surg. 2016;51(12):1907-1913. doi:10.1016/j.jpedsurg.2016.09.011.

16. Denning TW, Bhatia AM, Kane AF, Patel RM, Denning PW. Pathogenesis of NEC: Role of the innate and adaptive immune response. Semin Perinatol. 2017;41(1):15-28. doi:10.1053/j.semperi.2016.09.014.

17. Hodzic Z, Bolock AM, Good M. The Role of Mucosal Immunity in the Pathogenesis of Necrotizing Enterocolitis. Front Pediatr. 2017;5:40. doi:10.3389/fped.2017.00040.

18. Neu J, Pammi M. Pathogenesis of NEC: Impact of an altered intestinal microbiome. Semin Perinatol. 2017;41(1):29-35. doi:10.1053/j.semperi.2016.09.015.

19. Garzoni L, Faure C, Frasch MG. Fetal cholinergic anti-inflammatory pathway and necrotizing enterocolitis: the brain-gut connection begins in utero. Front Integr Neurosci. 2013;7:57. doi:10.3389/fnint.2013.00057.

20. Emami CN, Petrosyan M, Giuliani S, et al. Role of the host defense system and intestinal microbial flora in the pathogenesis of necrotizing enterocolitis. Surg Infect. 2009;10(5):407-417. doi:10.1089/sur.2009.054.

21. Hackam DJ, Upperman JS, Grishin A, Ford HR. Disordered enterocyte signaling and intestinal barrier dysfunction in the pathogenesis of necrotizing enterocolitis. Semin Pediatr Surg. 2005;14(1):49-57.

22. Daneman A, Woodward S, de Silva M. The radiology of neonatal necrotizing enterocolitis (NEC). A review of 47 cases and the literature. Pediatr Radiol. $1978 ; 7(2): 70-77$.

23. Sharma R, Tepas JJ, Hudak ML, et al. Portal venous gas and surgical outcome of neonatal necrotizing enterocolitis. J Pediatr Surg. 2005;40(2):371-376. doi:10.1016/j.jpedsurg.2004.10.022.

24. Dördelmann M, Rau GA, Bartels D, et al. Evaluation of portal venous gas detected by ultrasound examination for diagnosis of necrotising enterocolitis. Arch Child Fetal Neonatal Ed. 2009;94(3):F183-7. doi:10.1136/adc.2007.132019.

25. Llanos AR, Moss ME, Pinzòn MC, Dye T, Sinkin RA, Kendig JW. Epidemiology of neonatal necrotising enterocolitis: a population-based study. Paediatr Perinat Epidemiol. 2002;16(4):342-349. 
26. Sharma R, Hudak ML, Tepas JJ, et al. Impact of gestational age on the clinical presentation and surgical outcome of necrotizing enterocolitis. J Perinatol. 2006;26(6):342-347. doi:10.1038/sj.jp.7211510.

27. Yee WH, Soraisham AS, Shah VS, et al. Incidence and timing of presentation of necrotizing enterocolitis in preterm infants. Pediatrics. 2012;129(2):e298-304. doi:10.1542/peds.2011-2022.

28. Palmer SR, Biffin A, Gamsu HR. Outcome of neonatal necrotising enterocolitis: results of the BAPM/CDSC surveillance study, 1981-84. Arch Child. 1989;64(3):388-394.

29. Maayan-Metzger A, Itzchak A, Mazkereth R, Kuint J. Necrotizing enterocolitis in full-term infants: case-control study and review of the literature. J Perinatol Off J Calif Perinat Assoc. 2004;24(8):494-499. doi:10.1038/sj.jp.7211135.

30. Gordon PV, Swanson JR. Necrotizing enterocolitis is one disease with many origins and potential means of prevention. Pathophysiology. 2014;21(1):13-19. doi:10.1016/j.pathophys.2013.11.015.

31. Tam AL, Camberos A, Applebaum H. Surgical decision making in necrotizing enterocolitis and focal intestinal perforation: predictive value of radiologic findings. J Pediatr Surg. 2002;37(12):1688-1691. doi:10.1053/jpsu.2002.36696.

32. Zani A, Eaton S, Puri P, et al. International Survey on the Management of Necrotizing Enterocolitis. Eur J Pediatr Surg. 2014;25(01):27-33. doi:10.1055/s0034-1387942.

33. Blakely ML, Lally KP, McDonald S, et al. Postoperative outcomes of extremely low birth-weight infants with necrotizing enterocolitis or isolated intestinal perforation: a prospective cohort study by the NICHD Neonatal Research Network. Ann Surg. 2005;241(6):984-989; discussion 989-994.

34. Bohnhorst B, Kuebler JF, Rau G, Gluer S, Ure B, Doerdelmann M. Portal venous gas detected by ultrasound differentiates surgical NEC from other acquired neonatal intestinal diseases. Eur J Pediatr Surg. 2011;21(1):12-17. doi:10.1055/s0030-1265204.

35. Allin B, Long A-M, Gupta A, Knight M, Lakhoo K, British Association of Paediatric Surgeons Congenital Anomalies Surveillance System Necrotising Enterocolitis Collaboration. A UK wide cohort study describing management and outcomes for infants with surgical Necrotising Enterocolitis. Sci Rep. 2017;7:41149. doi:10.1038/srep41149. 
36. Neu J. Necrotizing Enterocolitis: The Mystery Goes On. Neonatology. 2014;106(4):289-295. doi:10.1159/000365130.

37. Rabinowitz JG, Siegle RL. Changing clinical and roentgenographic patterns of necrotizing enterocolitis. AJR Am J Roentgenol. 1976;126(3):560-566. doi:10.2214/ajr.126.3.560.

38. Morrison SC, Jacobson JM. The radiology of necrotizing enterocolitis. Clin Perinatol. 1994;21(2):347-363.

39. Silva CT, Daneman A, Navarro OM, et al. Correlation of sonographic findings and outcome in necrotizing enterocolitis. Pediatr Radiol. 2007;37(3):274-282. doi:10.1007/s00247-006-0393-x.

40. Siegle RL, Rabinowitz JG, Korones SB, Eyal FG. Early diagnosis of necrotizing enterocolitis. AJR Am J Roentgenol. 1976;127(4):629-632. doi:10.2214/ajr.127.4.629.

41. Kogutt MS. Necrotizing enterocolitis of infancy. Early roentgen patterns as a guide to prompt diagnosis. Radiology. 1979;130(2):367-370. doi:10.1148/130.2.367.

42. McBride WJ, Roy S, Brudnicki A, Stringel G. Correlation of complex ascites with intestinal gangrene and perforation in neonates with necrotizing enterocolitis. J Pediatr Surg. 2010;45(5):887-889.

doi:10.1016/j.jpedsurg.2010.02.011.

43. Rehan VK, Seshia MM, Johnston B, Reed M, Wilmot D, Cook V. Observer variability in interpretation of abdominal radiographs of infants with suspected necrotizing enterocolitis. Clin Pediatr Phila. 1999;38(11):637-643.

44. Merritt CR, Goldsmith JP, Sharp MJ. Sonographic detection of portal venous gas in infants with necrotizing enterocolitis. AJR Am J Roentgenol. 1984;143(5):1059-1062. doi:10.2214/ajr.143.5.1059.

45. Van Bel F, Van Zwieten PH, Guit GL, Schipper J. Superior mesenteric artery blood flow velocity and estimated volume flow: duplex Doppler US study of preterm and term neonates. Radiology. 1990;174(1):165-169. doi:10.1148/radiology.174.1.2403678.

46. Fotter R, Sorantin E. Diagnostic imaging in necrotizing enterocolitis. Acta Paediatr Suppl. 1994;396:41-44.

47. Di Napoli A, Di Lallo D, Perucci CA, et al. Inter-observer reliability of radiological signs of necrotising enterocolitis in a population of high-risk newborns. Paediatr Perinat Epidemiol. 2004;18(1):80-87. 
48. Mata AG, Rosengart RM. Interobserver variability in the radiographic diagnosis of necrotizing enterocolitis. Pediatrics. 1980;66(1):68-71.

49. Coursey CA, Hollingsworth CL, Gaca AM, Maxfield C, Delong D, Bisset G. Radiologists' agreement when using a 10-point scale to report abdominal radiographic findings of necrotizing enterocolitis in neonates and infants. AJR Am J Roentgenol. 2008;191(1):190-197. doi:10.2214/AJR.08.1090.

50. Coursey CA, Hollingsworth CL, Wriston C, Beam C, Rice H, Bisset G. Radiographic predictors of disease severity in neonates and infants with necrotizing enterocolitis. AJR Am J Roentgenol. 2009;193(5):1408-1413. doi:10.2214/AJR.08.2306.

51. Markiet K, Szymanska-Dubowik A, Janczewska I, Domazalska-Popadiuk I, Zawadzka-Kepczynska A, Bianek-Bodzak A. Agreement and reproducibility of radiological signs in NEC using The Duke Abdominal Assessment Scale (DAAS). Pediatr Surg Int. 2017;33(3):335-340. doi:10.1007/s00383-016-4022-y.

52. Bohnhorst B. Usefulness of abdominal ultrasound in diagnosing necrotising enterocolitis. Arch Child Fetal Neonatal Ed. 2013;98(5):F445-50. doi:10.1136/archdischild-2012-302848.

53. Muchantef K, Epelman M, Darge K, Kirpalani H, Laje P, Anupindi SA. Sonographic and radiographic imaging features of the neonate with necrotizing enterocolitis: correlating findings with outcomes. Pediatr Radiol. 2013;43(11):1444-1452. doi:10.1007/s00247-013-2725-y.

54. Robberecht EA, Afschrift M, De Bel CE, et al. Sonographic demonstration of portal venous gas in necrotizing enterocolitis. Eur J Pediatr. 1988;147(2):192-194.

55. Pickworth FE, Franklin K. Case report: ultrasound diagnosis of unsuspected necrotizing enterocolitis. Clin Radiol. 1994;49(9):649-651.

56. Kosloske AM, Musemeche CA, Ball WS, Ablin DS, Bhattacharyya N. Necrotizing enterocolitis: value of radiographic findings to predict outcome. AJR Am J Roentgenol. 1988;151(4):771-774. doi:10.2214/ajr.151.4.771.

57. Molik KA, West KW, Rescorla FJ, Scherer LR, Engum SA, Grosfeld JL. Portal venous air: the poor prognosis persists. J Pediatr Surg. 2001;36(8):1143-1145. doi:10.1053/jpsu.2001.25732.

58. Roy A, Tayeb M, Khogeer SS, Al-Salem AH. Predictors of gangrenous necrotizing enterocolitis and extent of disease. Early laparotomy versus peritoneal drainage. Saudi Med J. 2005;26(3):447-452. 
59. He Y, Zhong Y, Yu J, Cheng C, Wang Z, Li L. Ultrasonography and radiography findings predicted the need for surgery in patients with necrotising enterocolitis without pneumoperitoneum. Acta Paediatr Oslo Nor 1992. 2016;105(4):e151-155. doi:10.1111/apa.13315.

60. Kim WY, Kim WS, Kim IO, Kwon TH, Chang W, Lee EK. Sonographic evaluation of neonates with early-stage necrotizing enterocolitis. Pediatr Radiol. 2005;35(11):1056-1061. doi:10.1007/s00247-005-1533-4.

61. Dilli D, Suna Oğuz S, Erol R, Ozkan-Ulu H, Dumanlı H, Dilmen U. Does abdominal sonography provide additional information over abdominal plain radiography for diagnosis of necrotizing enterocolitis in neonates? Pediatr Surg Int. 2011;27(3):321-327. doi:10.1007/s00383-010-2737-8.

62. Coombs RC, Morgan ME, Durbin GM, Booth IW, McNeish AS. Abnormal gut blood flow velocities in neonates at risk of necrotising enterocolitis. J Pediatr Gastroenterol Nutr. 1992;15(1):13-19.

63. Kempley ST, Gamsu HR. Superior mesenteric artery blood flow velocity in necrotising enterocolitis. Arch Dis Child. 1992;67(7 Spec No):793-796.

64. Deeg KH, Rupprecht T, Schmid E. Doppler sonographic detection of increased flow velocities in the celiac trunk and superior mesenteric artery in infants with necrotizing enterocolitis. Pediatr Radiol. 1993;23(8):578-582.

65. Riccabona M, Joannou A, Maurer U, Müller W, Schwinger W. [Doppler ultrasound in necrotizing enterocolitis]. Z Geburtshilfe Perinatol. 1993;197(2):8789.

66. Schmidt H, Schramm A. [The corroborative capacity and value of imaging diagnosis and duplex sonography in newborn infants with necrotizing enterocolitis]. ROFO Fortschr Geb Rontgenstr Nuklearmed. 1994;160(6):524-530. doi:10.1055/s-2008-1032471.

67. Hashem RH, Mansi YA, Almasah NS, Abdelghaffar S. Doppler ultrasound assessment of the splanchnic circulation in preterms with neonatal sepsis at risk for necrotizing enterocolitis. J Ultrasound. 2017;20(1):59-67. doi:10.1007/s40477-016-0228-z.

68. Palleri E, Kaiser S, Wester T, Arnell H, Bartocci M. Complex Fluid Collection on Abdominal Ultrasound Indicates Need for Surgery in Neonates with Necrotizing Enterocolitis. Eur J Pediatr Surg. March 2016. doi:10.1055/s-00361580702. 
69. Miller SF, Seibert JJ, Kinder DL, Wilson AR. Use of ultrasound in the detection of occult bowel perforation in neonates. J Ultrasound Med Off J Am Inst Ultrasound Med. 1993;12(9):531-535.

70. Faingold R, Daneman A, Tomlinson G, et al. Necrotizing enterocolitis: assessment of bowel viability with color doppler US. Radiology. 2005;235(2):587594. doi:10.1148/radiol.2352031718.

71. Yikilmaz A, Hall NJ, Daneman A, et al. Prospective evaluation of the impact of sonography on the management and surgical intervention of neonates with necrotizing enterocolitis. Pediatr Surg Int. 2014;30(12):1231-1240. doi:10.1007/s00383-014-3613-8.

72. Silva CT, Daneman A, Navarro OM, Moineddin R, Levine D, Moore AM. A prospective comparison of intestinal sonography and abdominal radiographs in a neonatal intensive care unit. Pediatr Radiol. 2013;43(11):1453-1463. doi:10.1007/s00247-013-2777-z.

73. Leonard T, Johnson JF, Pettett PG. Critical evaluation of the persistent loop sign in necrotizing enterocolitis. Radiology. 1982;142(2):385-386.

doi:10.1148/radiology.142.2.7054826.

74. Cikrit D, Mastandrea J, Grosfeld JL, West KW, Schreiner RL. Significance of portal vein air in necrotizing entercolitis: analysis of 53 cases. J Pediatr Surg. 1985;20(4):425-430.

75. Frey EE, Smith W, Franken EA, Wintermeyer KA. Analysis of bowel perforation in necrotizing enterocolitis. Pediatr Radiol. 1987;17(5):380-382.

76. Kennedy J, Holt CL, Ricketts RR. The significance of portal vein gas in necrotizing enterocolitis. Am Surg. 1987;53(4):231-234.

77. Brill PW, Olson SR, Winchester P. Neonatal necrotizing enterocolitis: air in Morison pouch. Radiology. 1990;174(2):469-471.

doi:10.1148/radiology.174.2.2296656.

78. Bömelburg T, von Lengerke HJ. Sonographic findings in infants with suspected necrotizing enterocolitis. Eur J Radiol. 1992;15(2):149-153.

79. Muller A, Schurink M, Bos AF, et al. Clinical importance of a fixed bowel loop in the treatment of necrotizing enterocolitis. Neonatology. 2014;105(1):33-38. doi:10.1159/000355064.

80. Lindley S, Mollitt DL, Seibert JJ, Golladay ES. Portal vein ultrasonography in the early diagnosis of necrotizing enterocolitis. J Pediatr Surg. 1986;21(6):530532 . 
81. Kawase Y, Ishii T, Arai H, Uga N. Gastrointestinal perforation in very lowbirthweight infants. Pediatr Int. 2006;48(6):599-603. doi:10.1111/j.1442200X.2006.02282.x.

82. Sankaran K, Puckett B, Lee DS, et al. Variations in incidence of necrotizing enterocolitis in Canadian neonatal intensive care units. J Pediatr Gastroenterol Nutr. 2004;39(4):366-372.

83. Holman RC, Stoll BJ, Clarke MJ, Glass RI. The epidemiology of necrotizing enterocolitis infant mortality in the United States. Am J Public Health. 1997;87(12):2026-2031.

84. Wilson R, Kanto WP, McCarthy BJ, et al. Epidemiologic characteristics of necrotizing enterocolitis: a population-based study. Am J Epidemiol. 1981;114(6):880-887.

85. Guner YS, Friedlich P, Wee CP, Dorey F, Camerini V, Upperman JS. Statebased analysis of necrotizing enterocolitis outcomes. J Surg Res. 2009;157(1):2129. doi:10.1016/j.jss.2008.11.008.

86. Bertino E, Giuliani F, Prandi G, Coscia A, Martano C, Fabris C. Necrotizing enterocolitis: risk factor analysis and role of gastric residuals in very low birth weight infants. J Pediatr Gastroenterol Nutr. 2009;48(4):437-442.

87. Bain J, Benjamin DK, Hornik CP, Benjamin DK, Clark R, Smith PB. Risk of necrotizing enterocolitis in very-low-birth-weight infants with isolated atrial and ventricular septal defects. J Perinatol Off J Calif Perinat Assoc. 2014;34(4):319321. doi:10.1038/jp.2013.174.

88. Walther FJ, Verloove-Vanhorick SP, Brand R, Ruys JH. A prospective survey of necrotising enterocolitis in very low birthweight infants. Paediatr Perinat Epidemiol. 1989;3(1):53-61.

89. Moro M, Pérez-Rodriguez J, Figueras-Aloy J, et al. Predischarge morbidities in extremely and very low-birth-weight infants in Spanish neonatal units. Am J Perinatol. 2009;26(5):335-343. doi:10.1055/s-0028-1110083.

90. EXPRESS Group. Incidence of and risk factors for neonatal morbidity after active perinatal care: extremely preterm infants study in Sweden (EXPRESS). Acta Paediatr Oslo Nor 1992. 2010;99(7):978-992. doi:10.1111/j.16512227.2010.01846.x.

91. Ahle M, Drott P, Andersson RE. Epidemiology and trends of necrotizing enterocolitis in Sweden: 1987-2009. Pediatrics. 2013;132(2):e443-51. doi:10.1542/peds.2012-3847. 
92. Thilo EH, Lazarte RA, Hernandez JA. Necrotizing enterocolitis in the first 24 hours of life. Pediatrics. 1984;73(4):476-480.

93. Polin RA, Pollack PF, Barlow B, et al. Necrotizing enterocolitis in term infants. J Pediatr. 1976;89(3):460-462.

94. Kliegman RM, Hack M, Jones P, Fanaroff AA. Epidemiologic study of necrotizing enterocolitis among low-birth-weight infants. Absence of identifiable risk factors. J Pediatr. 1982;100(3):440-444.

95. Wiswell TE, Robertson CF, Jones TA, Tuttle DJ. Necrotizing enterocolitis in full-term infants. A case-control study. Am J Dis Child 1960. 1988;142(5):532-535.

96. Andrews DA, Sawin RS, Ledbetter DJ, Schaller RT, Hatch EI. Necrotizing enterocolitis in term neonates. Am J Surg. 1990;159(5):507-509.

97. Beeby PJ, Jeffery H. Risk factors for necrotising enterocolitis: the influence of gestational age. Arch Dis Child. 1992;67(4 Spec No):432-435.

98. Holman RC, Stehr-Green JK, Zelasky MT. Necrotizing enterocolitis mortality in the United States, 1979-85. Am J Public Health. 1989;79(8):987-989.

99. Luig M, Lui K, NSW \& ACT NICUS Group. Epidemiology of necrotizing enterocolitis--Part I: Changing regional trends in extremely preterm infants over 14 years. J Paediatr Child Health. 2005;41(4):169-173. doi:10.1111/j.14401754.2005.00582.x.

100. Wendelboe AM, Smelser C, Lucero CA, McDonald LC. Cluster of necrotizing enterocolitis in a neonatal intensive care unit: New Mexico, 2007. Am J Infect Control. 2010;38(2):144-148. doi:10.1016/j.ajic.2009.06.009.

101. van Acker J, de Smet F, Muyldermans G, Bougatef A, Naessens A, Lauwers S. Outbreak of necrotizing enterocolitis associated with Enterobacter sakazakii in powdered milk formula. J Clin Microbiol. 2001;39(1):293-297. doi:10.1128/JCM.39.1.293-297.2001.

102. Stuart RL, Tan K, Mahar JE, et al. An outbreak of necrotizing enterocolitis associated with norovirus genotype GII.3. Pediatr Infect Dis J. 2010;29(7):644647.

103. Guinan M, Schaberg D, Bruhn FW, Richardson CJ, Fox WW. Epidemic occurrence of neonatal necrotizing enterocolitis. Am J Dis Child 1960. 1979;133(6):594-597. 
104. Sdona E, Papamichail D, Panagiotopoulos T, Lagiou P, Malamitsi-Puchner A. Cluster of late preterm and term neonates with necrotizing enterocolitis symptomatology: descriptive and case-control study. J Matern-Fetal Neonatal Med Off J Eur Assoc Perinat Med Fed Asia Ocean Perinat Soc Int Soc Perinat Obstet. 2016;29(20):3329-3334. doi:10.3109/14767058.2015.1125461.

105. Snyder CL, Hall M, Sharma V, St Peter SD. Seasonal variation in the incidence of necrotizing enterocolitis. Pediatr Surg Int. 2010;26(9):895-898. doi:10.1007/s00383-010-2675-5.

106. Lu Q, Cheng S, Zhou M, Yu J. Risk Factors for Necrotizing Enterocolitis in Neonates: A Retrospective Case-Control Study. Pediatr Neonatol. 2017;58(2):165170. doi:10.1016/j.pedneo.2016.04.002.

107. Hunter CJ, Upperman JS, Ford HR, Camerini V. Understanding the susceptibility of the premature infant to necrotizing enterocolitis (NEC). Pediatr Res. 2008;63(2):117-123. doi:10.1203/PDR.0b013e31815ed64c.

108. Turcios-Ruiz RM, Axelrod P, St John K, et al. Outbreak of necrotizing enterocolitis caused by norovirus in a neonatal intensive care unit. J Pediatr. 2008;153(3):339-344. doi:10.1016/j.jpeds.2008.04.015.

109. Peter CS, Feuerhahn M, Bohnhorst B, et al. Necrotising enterocolitis: is there a relationship to specific pathogens? Eur J Pediatr. 1999;158(1):67-70.

110. Lemyre B, Xiu W, Bouali NR, et al. A decrease in the number of cases of necrotizing enterocolitis associated with the enhancement of infection prevention and control measures during a Staphylococcus aureus outbreak in a neonatal intensive care unit. Infect Control Hosp Epidemiol. 2012;33(1):29-33. doi:10.1086/663343.

111. Palmer SR, Thomas SJ, Cooke RW, et al. Birthweight-specific risk factors for necrotising enterocolitis. J Epidemiol Community Health. 1987;41(3):210-214.

112. Lambert DK, Christensen RD, Henry E, et al. Necrotizing enterocolitis in term neonates: data from a multihospital health-care system. J Perinatol Off J Calif Perinat Assoc. 2007;27(7):437-443. doi:10.1038/sj.jp.7211738.

113. Bolisetty S, Lui K, Oei J, Wojtulewicz J. A regional study of underlying congenital diseases in term neonates with necrotizing enterocolitis. Acta Paediatr Oslo Nor 1992. 2000;89(10):1226-1230.

114. Martinez-Tallo E, Claure N, Bancalari E. Necrotizing enterocolitis in full-term or near-term infants: risk factors. Biol Neonate. 1997;71(5):292-298. 
115. Ostlie DJ, Spilde TL, St Peter SD, et al. Necrotizing enterocolitis in full-term infants. J Pediatr Surg. 2003;38(7):1039-1042.

116. Bhandari V, Bizzarro MJ, Shetty A, et al. Familial and genetic susceptibility to major neonatal morbidities in preterm twins. Pediatrics. 2006;117(6):1901-1906. doi:10.1542/peds.2005-1414.

117. Cuna A, Sampath V. Genetic alterations in necrotizing enterocolitis. Semin Perinatol. 2017;41(1):61-69. doi:10.1053/j.semperi.2016.09.019.

118. Cetinkaya M, Ozkan H, Koksal N. Maternal preeclampsia is associated with increased risk of necrotizing enterocolitis in preterm infants. Early Hum Dev. 2012;88(11):893-898. doi:10.1016/j.earlhumdev.2012.07.004.

119. Bashiri A, Zmora E, Sheiner E, Hershkovitz R, Shoham-Vardi I, Mazor M. Maternal hypertensive disorders are an independent risk factor for the development of necrotizing enterocolitis in very low birth weight infants. Fetal Diagn Ther. 2003;18(6):404-407. doi:73132.

120. Perger L, Mukhopadhyay D, Komidar L, Wiggins-Dohlvik K, Uddin MN, Beeram M. Maternal pre-eclampsia as a risk factor for necrotizing enterocolitis. J Matern-Fetal Neonatal Med Off J Eur Assoc Perinat Med Fed Asia Ocean Perinat Soc Int Soc Perinat Obstet. 2016;29(13):2098-2103. doi:10.3109/14767058.2015.1076386.

121. March MI, Gupta M, Modest AM, et al. Maternal risk factors for neonatal necrotizing enterocolitis. J Matern-Fetal Neonatal Med Off J Eur Assoc Perinat Med Fed Asia Ocean Perinat Soc Int Soc Perinat Obstet. August 2014:1-6. doi:10.3109/14767058.2014.951624.

122. Vieira AA, David BBL, Lino RRG, Duarte L de B, Bueno AC. [Evaluation of perinatal factors that influence the incidence of necrotizing enterocolitis in very low birth weight infants]. Rev Bras Ginecol E Obstet Rev Fed Bras Soc Ginecol E Obstet. 2013;35(8):363-367.

123. Boo N-Y, Cheah IGS. Risk factors associated with necrotising enterocolitis in very low birth weight infants in Malaysian neonatal intensive care units. Singapore Med J. 2012;53(12):826-831.

124. Kenyon S, Boulvain M, Neilson JP. Antibiotics for preterm rupture of membranes. Cochrane Database Syst Rev. 2013;(12):CD001058. doi:10.1002/14651858.CD001058.pub3. 
125. Seeman SM, Mehal JM, Haberling DL, Holman RC, Stoll BJ. Infant and maternal risk factors related to necrotising enterocolitis-associated infant death in the United States. Acta Paediatr. 2016;105(6):e240-e246. doi:10.1111/apa.13390.

126. Downard CD, Grant SN, Maki AC, et al. Maternal cigarette smoking and the development of necrotizing enterocolitis. Pediatrics. 2012;130(1):78-82. doi:10.1542/peds.2011-3808.

127. Stout G, Lambert DK, Baer VL, et al. Necrotizing enterocolitis during the first week of life: a multicentered case-control and cohort comparison study. J Perinatol Off J Calif Perinat Assoc. 2008;28(8):556-560. doi:10.1038/jp.2008.36.

128. Karpelowsky JS, van Mil S, Numanoglu A, Leva E, Millar AJW. Effect of maternal human immunodeficiency virus status on the outcome of neonates with necrotizing enterocolitis. J Pediatr Surg. 2010;45(2):315-318; discussion 318. doi:10.1016/j.jpedsurg.2009.10.068.

129. Desfrere L, de Oliveira I, Goffinet F, et al. Increased incidence of necrotizing enterocolitis in premature infants born to HIV-positive mothers. AIDS Lond Engl. 2005;19(14):1487-1493.

130. Sood BG, Lulic-Botica M, Holzhausen KA, et al. The risk of necrotizing enterocolitis after indomethacin tocolysis. Pediatrics. 2011;128(1):e54-62. doi:10.1542/peds.2011-0265.

131. García-Muñoz Rodrigo F, Galán Henríquez G, Figueras Aloy J, García-Alix Pérez A. Outcomes of very-low-birth-weight infants exposed to maternal clinical chorioamnionitis: a multicentre study. Neonatology. 2014;106(3):229-234. doi:10.1159/000363127.

132. Gagliardi L, Rusconi F, Bellù R, Zanini R, Italian Neonatal Network. Association of maternal hypertension and chorioamnionitis with preterm outcomes. Pediatrics. 2014;134(1):e154-161. doi:10.1542/peds.2013-3898.

133. Been JV, Lievense S, Zimmermann LJI, Kramer BW, Wolfs TGAM. Chorioamnionitis as a risk factor for necrotizing enterocolitis: a systematic review and meta-analysis. J Pediatr. 2013;162(2):236-242.e2. doi:10.1016/j.jpeds.2012.07.012.

134. Moore SW, Arnold M, Wright C. Necrotizing enterocolitis and the placenta - a key etiological link. J Pediatr Surg. 2013;48(2):359-362. doi:10.1016/j.jpedsurg.2012.11.020. 
135. Wójkowska-Mach J, Różańska A, Borszewska-Kornacka M, et al. Necrotising enterocolitis in preterm infants: epidemiology and antibiotic consumption in the Polish neonatology network neonatal intensive care units in 2009. PloS One. 2014;9(3):e92865. doi:10.1371/journal.pone.0092865.

136. Luig M, Lui K, NSW \& ACT NICUS Group. Epidemiology of necrotizing enterocolitis--Part II: Risks and susceptibility of premature infants during the surfactant era: a regional study. J Paediatr Child Health. 2005;41(4):174-179. doi:10.1111/j.1440-1754.2005.00583.x.

137. Westby Eger SH, Kessler J, Kiserud T, Markestad T, Sommerfelt K. Foetal Doppler abnormality is associated with increased risk of sepsis and necrotising enterocolitis in preterm infants. Acta Paediatr Oslo Nor 1992. 2015;104(4):368-376. doi:10.1111/apa.12893.

138. Manogura AC, Turan O, Kush ML, et al. Predictors of necrotizing enterocolitis in preterm growth-restricted neonates. Am J Obstet Gynecol. 2008;198(6):638.e15. doi:10.1016/j.ajog.2007.11.048.

139. Guthrie SO, Gordon PV, Thomas V, Thorp JA, Peabody J, Clark RH. Necrotizing enterocolitis among neonates in the United States. J Perinatol Off J Calif Perinat Assoc. 2003;23(4):278-285. doi:10.1038/sj.jp.7210892.

140. Holman RC, Stoll BJ, Curns AT, Yorita KL, Steiner CA, Schonberger LB. Necrotising enterocolitis hospitalisations among neonates in the United States. Paediatr Perinat Epidemiol. 2006;20(6):498-506. doi:10.1111/j.13653016.2006.00756.x.

141. Bernstein IM, Horbar JD, Badger GJ, Ohlsson A, Golan A. Morbidity and mortality among very-low-birth-weight neonates with intrauterine growth restriction. The Vermont Oxford Network. Am J Obstet Gynecol. 2000;182(1 Pt 1):198-206.

142. Westby Wold SH, Sommerfelt K, Reigstad H, et al. Neonatal mortality and morbidity in extremely preterm small for gestational age infants: a population based study. Arch Dis Child Fetal Neonatal Ed. 2009;94(5):F363-367. doi:10.1136/adc.2009.157800.

143. Ree IMC, Smits-Wintjens VEHJ, Rijntjes-Jacobs EGJ, et al. Necrotizing enterocolitis in small-for-gestational-age neonates: a matched case-control study. Neonatology. 2014;105(1):74-78. doi:10.1159/000356033.

144. Al Tawil K, Sumaily H, Ahmed IA, et al. Risk factors, characteristics and outcomes of necrotizing enterocolitis in late preterm and term infants. J Neonatal-Perinat Med. 2013;6(2):125-130. doi:10.3233/NPM-1365912. 
145. Fisher JG, Bairdain S, Sparks EA, et al. Serious congenital heart disease and necrotizing enterocolitis in very low birth weight neonates. J Am Coll Surg. 2015;220(6):1018-1026.e14. doi:10.1016/j.jamcollsurg.2014.11.026.

146. Grosfeld JL, Chaet M, Molinari F, et al. Increased risk of necrotizing enterocolitis in premature infants with patent ductus arteriosus treated with indomethacin. Ann Surg. 1996;224(3):350-355; discussion 355-357.

147. Youn YA, Kim E-K, Kim SY. Necrotizing Enterocolitis among Very-Low-BirthWeight Infants in Korea. J Korean Med Sci. 2015;30 Suppl 1:S75-80. doi:10.3346/jkms.2015.30.S1.S75.

148. Wilson R, del Portillo M, Schmidt E, Feldman RA, Kanto WP. Risk factors for necrotizing enterocolitis in infants weighing more than 2,000 grams at birth: a case-control study. Pediatrics. 1983;71(1):19-22.

149. McElhinney DB, Hedrick HL, Bush DM, et al. Necrotizing enterocolitis in neonates with congenital heart disease: risk factors and outcomes. Pediatrics. 2000;106(5):1080-1087.

150. Paul DA, Mackley A, Novitsky A, Zhao Y, Brooks A, Locke RG. Increased odds of necrotizing enterocolitis after transfusion of red blood cells in premature infants. Pediatrics. 2011;127(4):635-641. doi:10.1542/peds.2010-3178.

151. Blau J, Calo JM, Dozor D, Sutton M, Alpan G, La Gamma EF. Transfusionrelated acute gut injury: necrotizing enterocolitis in very low birth weight neonates after packed red blood cell transfusion. J Pediatr. 2011;158(3):403-409. doi:10.1016/j.jpeds.2010.09.015.

152. Bak S-Y, Lee S, Park J-H, Park K-H, Jeon J-H. Analysis of the association between necrotizing enterocolitis and transfusion of red blood cell in very low birth weight preterm infants. Korean J Pediatr. 2013;56(3):112-115. doi:10.3345/kjp.2013.56.3.112.

153. Valieva OA, Strandjord TP, Mayock DE, Juul SE. Effects of transfusions in extremely low birth weight infants: a retrospective study. J Pediatr. 2009;155(3):331-337.e1. doi:10.1016/j.jpeds.2009.02.026.

154. Mohamed A, Shah PS. Transfusion associated necrotizing enterocolitis: a metaanalysis of observational data. Pediatrics. 2012;129(3):529-540. doi:10.1542/peds.2011-2872.

155. Sayari AJ, Tashiro J, Sola JE, Perez EA. Blood transfusions, increased rates of surgical NEC, and lower survival: a propensity score-matched analysis. J Pediatr Surg. 2016;51(6):927-931. doi:10.1016/j.jpedsurg.2016.02.052. 
156. Navarro M, Negre S, Matoses ML, Golombek SG, Vento M. Necrotizing enterocolitis following the use of intravenous immunoglobulin for haemolytic disease of the newborn. Acta Paediatr Oslo Nor 1992. 2009;98(7):1214-1217. doi:10.1111/j.1651-2227.2009.01279.x.

157. Figueras-Aloy J, Rodríguez-Miguélez JM, Iriondo-Sanz M, Salvia-Roiges M-D, Botet-Mussons F, Carbonell-Estrany X. Intravenous immunoglobulin and necrotizing enterocolitis in newborns with hemolytic disease. Pediatrics. 2010;125(1):139-144. doi:10.1542/peds.2009-0676.

158. Krishnan L, Pathare A. Necrotizing enterocolitis in a term neonate following intravenous immunoglobulin therapy. Indian J Pediatr. 2011;78(6):743-744. doi:10.1007/s12098-010-0334-4.

159. Yu C, Li H, Zhang Q, He H, Chen X, Hua Z. Report about term infants with severe hyperbilirubinemia undergoing exchange transfusion in Southwestern China during an 11-year period, from 2001 to 2011. PloS One. 2017;12(6):e0179550. doi:10.1371/journal.pone.0179550.

160. Guillet R, Stoll BJ, Cotten CM, et al. Association of H2-blocker therapy and higher incidence of necrotizing enterocolitis in very low birth weight infants. Pediatrics. 2006;117(2):e137-142. doi:10.1542/peds.2005-1543.

161. Terrin G, Passariello A, De Curtis M, et al. Ranitidine is associated with infections, necrotizing enterocolitis, and fatal outcome in newborns. Pediatrics. 2012;129(1):e40-45. doi:10.1542/peds.2011-0796.

162. Bilali A, Galanis P, Bartsocas C, Sparos L, Velonakis E. H2-blocker therapy and incidence of necrotizing enterocolitis in preterm infants: a case-control study. Pediatr Neonatol. 2013;54(2):141-142. doi:10.1016/j.pedneo.2013.01.011.

163. Cotten CM, Taylor S, Stoll B, et al. Prolonged duration of initial empirical antibiotic treatment is associated with increased rates of necrotizing enterocolitis and death for extremely low birth weight infants. Pediatrics. 2009;123(1):58-66. doi:10.1542/peds.2007-3423.

164. Alexander VN, Northrup V, Bizzarro MJ. Antibiotic exposure in the newborn intensive care unit and the risk of necrotizing enterocolitis. J Pediatr. 2011;159(3):392-397. doi:10.1016/j.jpeds.2011.02.035.

165. Kuppala VS, Meinzen-Derr J, Morrow AL, Schibler KR. Prolonged initial empirical antibiotic treatment is associated with adverse outcomes in premature infants. J Pediatr. 2011;159(5):720-725. doi:10.1016/j.jpeds.2011.05.033. 
166. Arayici S, Kadioglu Simsek G, Oncel MY, et al. The effect of histological chorioamnionitis on the short-term outcome of preterm infants $\leq 32$ weeks: a single-center study. J Matern-Fetal Neonatal Med Off J Eur Assoc Perinat Med Fed Asia Ocean Perinat Soc Int Soc Perinat Obstet. 2014;27(11):1129-1133. doi:10.3109/14767058.2013.850668.

167. Lee LCL, Tillett A, Tulloh R, Yates R, Kelsall W. Outcome following patent ductus arteriosus ligation in premature infants: a retrospective cohort analysis. BMC Pediatr. 2006;6:15. doi:10.1186/1471-2431-6-15.

168. Roberts D, Dalziel S. Antenatal corticosteroids for accelerating fetal lung maturation for women at risk of preterm birth. Cochrane Database Syst Rev. 2006;(3):CD004454. doi:10.1002/14651858.CD004454.pub2.

169. McKinlay CJD, Crowther CA, Middleton P, Harding JE. Repeat antenatal glucocorticoids for women at risk of preterm birth: a Cochrane Systematic Review. Am J Obstet Gynecol. 2012;206(3):187-194. doi:10.1016/j.ajog.2011.07.042.

170. Brownfoot FC, Gagliardi DI, Bain E, Middleton P, Crowther CA. Different corticosteroids and regimens for accelerating fetal lung maturation for women at risk of preterm birth. Cochrane Database Syst Rev. 2013;(8):CD006764. doi:10.1002/14651858.CD006764.pub3.

171. Herrera C, Holberton J, Davis P. Prolonged versus short course of indomethacin for the treatment of patent ductus arteriosus in preterm infants. Cochrane Database Syst Rev. 2007;(2):CD003480. doi:10.1002/14651858.CD003480.pub3.

172. Cunningham KE, Okolo FC, Baker R, Mollen KP, Good M. Red blood cell transfusion in premature infants leads to worse necrotizing enterocolitis outcomes. J Surg Res. 2017;213:158-165. doi:10.1016/j.jss.2017.02.029.

173. Nair J, Gugino SF, Nielsen LC, et al. Packed red cell transfusions alter mesenteric arterial reactivity and nitric oxide pathway in preterm lambs. Pediatr Res. 2013;74(6):652-657. doi:10.1038/pr.2013.153.

174. Josephson CD, Wesolowski A, Bao G, et al. Do red cell transfusions increase the risk of necrotizing enterocolitis in premature infants? J Pediatr. 2010;157(6):972978.e1-3. doi:10.1016/j.jpeds.2010.05.054.

175. Wallenstein MB, Arain $\mathrm{YH}$, Birnie KL, et al. Red blood cell transfusion is not associated with necrotizing enterocolitis: a review of consecutive transfusions in a tertiary neonatal intensive care unit. J Pediatr. 2014;165(4):678-682. doi:10.1016/j.jpeds.2014.06.012. 
176. Penn AH, Altshuler AE, Small JW, Taylor SF, Dobkins KR, Schmid-Schönbein GW. Digested formula but not digested fresh human milk causes death of intestinal cells in vitro: implications for necrotizing enterocolitis. Pediatr Res. 2012;72(6):560-567. doi:10.1038/pr.2012.125.

177. Lucas A, Cole TJ. Breast milk and neonatal necrotising enterocolitis. Lancet Lond Engl. 1990;336(8730):1519-1523.

178. Kosloske AM. Breast milk decreases the risk of neonatal necrotizing enterocolitis. Adv Nutr Res. 2001;10:123-137.

179. Sisk PM, Lovelady CA, Dillard RG, Gruber KJ, O'Shea TM. Early human milk feeding is associated with a lower risk of necrotizing enterocolitis in very low birth weight infants. J Perinatol Off J Calif Perinat Assoc. 2007;27(7):428-433. doi:10.1038/sj.jp.7211758.

180. Meinzen-Derr J, Poindexter B, Wrage L, Morrow AL, Stoll B, Donovan EF. Role of human milk in extremely low birth weight infants' risk of necrotizing enterocolitis or death. J Perinatol Off J Calif Perinat Assoc. 2009;29(1):57-62. doi:10.1038/jp.2008.117.

181. Sullivan S, Schanler RJ, Kim JH, et al. An exclusively human milk-based diet is associated with a lower rate of necrotizing enterocolitis than a diet of human milk and bovine milk-based products. J Pediatr. 2010;156(4):562-567.e1. doi:10.1016/j.jpeds.2009.10.040.

182. Cristofalo EA, Schanler RJ, Blanco CL, et al. Randomized trial of exclusive human milk versus preterm formula diets in extremely premature infants. J Pediatr. 2013;163(6):1592-1595.e1. doi:10.1016/j.jpeds.2013.07.011.

183. Herrmann K, Carroll K. An exclusively human milk diet reduces necrotizing enterocolitis. Breastfeed Med Off J Acad Breastfeed Med. 2014;9(4):184-190. doi:10.1089/bfm.2013.0121.

184. Lönnerdal B. Bioactive proteins in breast milk. J Paediatr Child Health. 2013;49 Suppl 1:1-7. doi:10.1111/jpc.12104.

185. Brandtzaeg P. The mucosal immune system and its integration with the mammary glands. J Pediatr. 2010;156(2 Suppl):S8-15. doi:10.1016/j.jpeds.2009.11.014.

186. Maffei D, Schanler RJ. Human milk is the feeding strategy to prevent necrotizing enterocolitis! Semin Perinatol. 2017;41(1):36-40. doi:10.1053/j.semperi.2016.09.016. 
187. Bury RG, Tudehope D. Enteral antibiotics for preventing necrotizing enterocolitis in low birthweight or preterm infants. Cochrane Database Syst Rev. 2001;(1):CD000405. doi:10.1002/14651858.CD000405.

188. Chandrasekaran M, Fleming P. Question 1: does the use of ranitidine increase the risk of NEC in preterm infants? Arch Dis Child. 2014;99(4):390-392. doi:10.1136/archdischild-2013-304973.

189. McCallie KR, Lee HC, Mayer O, Cohen RS, Hintz SR, Rhine WD. Improved outcomes with a standardized feeding protocol for very low birth weight infants. J Perinatol. 2011;31:S61-S67. doi:10.1038/jp.2010.185.

190. Talavera MM, Bixler G, Cozzi C, et al. Quality Improvement Initiative to Reduce the Necrotizing Enterocolitis Rate in Premature Infants. Pediatrics. 2016;137(5). doi:10.1542/peds.2015-1119.

191. Morgan J, Young L, McGuire W. Delayed introduction of progressive enteral feeds to prevent necrotising enterocolitis in very low birth weight infants. Cochrane Database Syst Rev. 2014;(12):CD001970. doi:10.1002/14651858.CD001970.pub5.

192. Morgan J, Bombell S, McGuire W. Early trophic feeding versus enteral fasting for very preterm or very low birth weight infants. Cochrane Database Syst Rev. 2013;(3):CD000504. doi:10.1002/14651858.CD000504.pub4.

193. Oddie SJ, Young L, McGuire W. Slow advancement of enteral feed volumes to prevent necrotising enterocolitis in very low birth weight infants. Cochrane Database Syst Rev. 2017;8:CD001241. doi:10.1002/14651858.CD001241.pub7.

194. Patole SK, de Klerk N. Impact of standardised feeding regimens on incidence of neonatal necrotising enterocolitis: a systematic review and meta-analysis of observational studies. Arch Dis Child Fetal Neonatal Ed. 2005;90(2):F147-151. doi:10.1136/adc.2004.059741.

195. Pammi M, Cope J, Tarr PI, et al. Intestinal dysbiosis in preterm infants preceding necrotizing enterocolitis: a systematic review and meta-analysis. Microbiome. 2017;5(1):31. doi:10.1186/s40168-017-0248-8.

196. Chang H-Y, Chen J-H, Chang J-H, Lin H-C, Lin C-Y, Peng C-C. Multiple strains probiotics appear to be the most effective probiotics in the prevention of necrotizing enterocolitis and mortality: An updated meta-analysis. PloS One. 2017;12(2):e0171579. doi:10.1371/journal.pone.0171579.

197. Gupta A, Paria A. Etiology and medical management of NEC. Early Hum Dev. 2016;97:17-23. doi:10.1016/j.earlhumdev.2016.03.008. 
198. Zani A, Pierro A. Necrotizing enterocolitis: controversies and challenges. F1000Res. 2015;4. doi:10.12688/f1000research.6888.1.

199. Rees CM, Hall NJ, Eaton S, Pierro A. Surgical strategies for necrotising enterocolitis: a survey of practice in the United Kingdom. Arch Dis Child Fetal Neonatal Ed. 2005;90(2):F152-155. doi:10.1136/adc.2004.051862.

200. Hull MA, Fisher JG, Gutierrez IM, et al. Mortality and management of surgical necrotizing enterocolitis in very low birth weight neonates: a prospective cohort study. J Am Coll Surg. 2014;218(6):1148-1155.

doi:10.1016/j.jamcollsurg.2013.11.015.

201. Heida FH, Stolwijk L, Loos M-LHJ, et al. Increased incidence of necrotizing enterocolitis in the Netherlands after implementation of the new Dutch guideline for active treatment in extremely preterm infants: Results from three academic referral centers. J Pediatr Surg. 2017;52(2):273-276. doi:10.1016/j.jpedsurg.2016.11.024.

202. Rees CM, Eaton S, Pierro A. National prospective surveillance study of necrotizing enterocolitis in neonatal intensive care units. J Pediatr Surg. 2010;45(7):1391-1397. doi:10.1016/j.jpedsurg.2009.12.002.

203. Robinson JR, Rellinger EJ, Hatch LD, et al. Surgical necrotizing enterocolitis. Semin Perinatol. 2017;41(1):70-79. doi:10.1053/j.semperi.2016.09.020.

204. Neu J, Mihatsch W. Recent developments in necrotizing enterocolitis. JPEN J Parenter Enter Nutr. 2012;36(1 Suppl):30S-5S. doi:10.1177/0148607111422068.

205. Ng PC, Ma TPY, Lam HS. The use of laboratory biomarkers for surveillance, diagnosis and prediction of clinical outcomes in neonatal sepsis and necrotising enterocolitis. Arch Dis Child Fetal Neonatal Ed. 2015;100(5):F448-452. doi:10.1136/archdischild-2014-307656.

206. Tepas JJ, Leaphart CL, Plumley D, et al. Trajectory of metabolic derangement in infants with necrotizing enterocolitis should drive timing and technique of surgical intervention. J Am Coll Surg. 2010;210(5):847-852, 852-854.

doi:10.1016/j.jamcollsurg.2010.01.008.

207. Gaudin A, Farnoux C, Bonnard A, et al. Necrotizing enterocolitis (NEC) and the risk of intestinal stricture: the value of C-reactive protein. PLoS One. 2013;8(10):e76858. doi:10.1371/journal.pone.0076858. 
208. Kastenberg ZJ, Lee HC, Profit J, Gould JB, Sylvester KG. Effect of deregionalized care on mortality in very low-birth-weight infants with necrotizing enterocolitis. JAMA Pediatr. 2015;169(1):26-32.

doi:10.1001/jamapediatrics.2014.2085.

209. Kelleher J, Mallick H, Soltau TD, Harmon CM, Dimmitt RA. Mortality and intestinal failure in surgical necrotizing enterocolitis. J Pediatr Surg. 2013;48(3):568-572. doi:10.1016/j.jpedsurg.2012.11.028.

210. Snyder CL, Gittes GK, Murphy JP, Sharp RJ, Ashcraft KW, Amoury RA. Survival after necrotizing enterocolitis in infants weighing less than 1,000 g: 25 years' experience at a single institution. J Pediatr Surg. 1997;32(3):434-437.

211. Markel TA, Engelstad H, Poindexter BB. Predicting disease severity of necrotizing enterocolitis: how to identify infants for future novel therapies. $J$ Clin Neonatol. 2014;3(1):1-9. doi:10.4103/2249-4847.128717.

212. Synnes A, Luu TM, Moddemann D, et al. Determinants of developmental outcomes in a very preterm Canadian cohort. Arch Dis Child Fetal Neonatal Ed. 2017;102(3):F235-F234. doi:10.1136/archdischild-2016-311228.

213. Serenius F, Källén K, Blennow M, et al. Neurodevelopmental outcome in extremely preterm infants at 2.5 years after active perinatal care in Sweden. JAMA. 2013;309(17):1810-1820. doi:10.1001/jama.2013.3786.

214. Wadhawan R, Oh W, Hintz SR, et al. Neurodevelopmental outcomes of extremely low birth weight infants with spontaneous intestinal perforation or surgical necrotizing enterocolitis. J Perinatol Off J Calif Perinat Assoc. 2014;34(1):64-70. doi:10.1038/jp.2013.128.

215. Elfvin A, Dinsdale E, Wales PW, Moore AM. Low birthweight, gestational age, need for surgical intervention and gram-negative bacteraemia predict intestinal failure following necrotising enterocolitis. Acta Paediatr Oslo Nor 1992. 2015;104(8):771-776. doi:10.1111/apa.12997.

216. Duro D, Kalish LA, Johnston P, et al. Risk factors for intestinal failure in infants with necrotizing enterocolitis: a Glaser Pediatric Research Network study. J Pediatr. 2010;157(2):203-208.e1. doi:10.1016/j.jpeds.2010.02.023.

217. Bouhlila DS, Sellaouti F. Multiple imputation using chained equations for missing data in TIMSS: a case study. Large-Scale Assess Educ. 2013;1(1):4. doi:10.1186/2196-0739-1-4.

218. Finnström O, Olausson PO, Sedin G, et al. The Swedish national prospective study on extremely low birthweight (ELBW) infants. Incidence, mortality, 
morbidity and survival in relation to level of care. Acta Paediatr Oslo Nor 1992. 1997;86(5):503-511.

219. Lundqvist P, Källén K, Hallström I, Westas LH. Trends in outcomes for very preterm infants in the southern region of Sweden over a 10-year period. Acta Paediatr Oslo Nor 1992. 2009;98(4):648-653. doi:10.1111/j.1651-2227.2008.01155.x.

220. Su Y-Y, Wang S-H, Chou H-C, et al. Morbidity and mortality of very low birth weight infants in Taiwan-Changes in 15 years: A population based study. $J$ Formos Med Assoc Taiwan Yi Zhi. 2016;115(12):1039-1045. doi:10.1016/j.jfma.2016.10.011.

221. Neu J. Probiotics and necrotizing enterocolitis. Clin Perinatol. 2014;41(4):967978. doi:10.1016/j.clp.2014.08.014.

222. Heida FH, van Zoonen AGJF, Hulscher JBF, et al. A Necrotizing EnterocolitisAssociated Gut Microbiota Is Present in the Meconium: Results of a Prospective Study. Clin Infect Dis Off Publ Infect Dis Soc Am. 2016;62(7):863-870. doi:10.1093/cid/ciw016.

223. Magnusson A, Ahle M, Swolin-Eide D, Elfvin A, Andersson RE. Populationbased study showed that necrotising enterocolitis occurred in space-time clusters with a decreasing secular trend in Sweden. Acta Paediatr Oslo Nor 1992. March 2017. doi:10.1111/apa.13851.

224. Samuels N, van de Graaf RA, de Jonge RCJ, Reiss IKM, Vermeulen MJ. Risk factors for necrotizing enterocolitis in neonates: a systematic review of prognostic studies. BMC Pediatr. 2017;17(1):105. doi:10.1186/s12887-017-0847-3.

225. Lee $\mathrm{Y}, \mathrm{Kim} \mathrm{H}-\mathrm{J}$, Choi S-J, et al. Is there a stepwise increase in neonatal morbidities according to histological stage (or grade) of acute chorioamnionitis and funisitis?: effect of gestational age at delivery. J Perinat Med. 2015;43(2):259267. doi:10.1515/jpm-2014-0035.

226. Lee J-Y, Park K-H, Kim A, Yang H-R, Jung E-Y, Cho S-H. Maternal and Placental Risk Factors for Developing Necrotizing Enterocolitis in Very Preterm Infants. Pediatr Neonatol. 2017;58(1):57-62. doi:10.1016/j.pedneo.2016.01.005.

227. Tomicić S, Johansson G, Voor T, Björkstén B, Böttcher MF, Jenmalm MC. Breast milk cytokine and IgA composition differ in Estonian and Swedish mothersrelationship to microbial pressure and infant allergy. Pediatr Res. 2010;68(4):330334. doi:10.1203/PDR.0b013e3181ee049d. 
228. Faucette AN, Pawlitz MD, Pei B, Yao F, Chen K. Immunization of pregnant women: Future of early infant protection. Hum Vaccines Immunother. 2015;11(11):2549-2555. doi:10.1080/21645515.2015.1070984.

229. Karlström A, Lindgren H, Hildingsson I. Maternal and infant outcome after caesarean section without recorded medical indication: findings from a Swedish case-control study. BJOG Int J Obstet Gynaecol. 2013;120(4):479-486; discussion 486. doi:10.1111/1471-0528.12129.

230. Paganelli S, Soncini E, Gargano G, Capodanno F, Vezzani C, La Sala GB. Retrospective analysis on the efficacy of corticosteroid prophylaxis prior to elective caesarean section to reduce neonatal respiratory complications at term of pregnancy: review of literature. Arch Gynecol Obstet. 2013;288(6):1223-1229. doi:10.1007/s00404-013-3035-1.

231. Rutayisire E, Huang K, Liu Y, Tao F. The mode of delivery affects the diversity and colonization pattern of the gut microbiota during the first year of infants' life: a systematic review. BMC Gastroenterol. 2016;16(1):86. doi:10.1186/s12876016-0498-0.

232. Hällström M, Eerola E, Vuento R, Janas M, Tammela O. Effects of mode of delivery and necrotising enterocolitis on the intestinal microflora in preterm infants. Eur J Clin Microbiol Infect Dis Off Publ Eur Soc Clin Microbiol. 2004;23(6):463-470. doi:10.1007/s10096-004-1146-0.

233. Warner BB, Deych E, Zhou Y, et al. Gut bacteria dysbiosis and necrotising enterocolitis in very low birthweight infants: a prospective case-control study. Lancet Lond Engl. 2016;387(10031):1928-1936. doi:10.1016/S0140-6736(16)00081-7.

234. Cabrera-Rubio R, Collado MC, Laitinen K, Salminen S, Isolauri E, Mira A. The human milk microbiome changes over lactation and is shaped by maternal weight and mode of delivery. Am J Clin Nutr. 2012;96(3):544-551. doi:10.3945/ajcn.112.037382.

235. Hobbs AJ, Mannion CA, McDonald SW, Brockway M, Tough SC. The impact of caesarean section on breastfeeding initiation, duration and difficulties in the first four months postpartum. BMC Pregnancy Childbirth. 2016;16:90. doi:10.1186/s12884-016-0876-1.

236. Härkin P, Marttila R, Pokka T, Saarela T, Hallman M. Morbidities associated with patent ductus arteriosus in preterm infants. Nationwide cohort study. $J$ Matern-Fetal Neonatal Med Off J Eur Assoc Perinat Med Fed Asia Ocean Perinat Soc Int Soc Perinat Obstet. July 2017:1-8. doi:10.1080/14767058.2017.1347921. 
237. Hällström M, Koivisto AM, Janas M, Tammela O. Frequency of and risk factors for necrotizing enterocolitis in infants born before 33 weeks of gestation. Acta Paediatr Oslo Nor 1992. 2003;92(1):111-113.

238. Murki S, Kumar P. Blood exchange transfusion for infants with severe neonatal hyperbilirubinemia. Semin Perinatol. 2011;35(3):175-184.

doi:10.1053/j.semperi.2011.02.013.

239. Roig JC, Burchfield DJ. Term neonates with hemolytic disease of the newborn and necrotizing enterocolitis: a report of two cases. J Perinatol Off J Calif Perinat Assoc. 1994;14(3):201-203.

240. Hay S, Zupancic JAF, Flannery DD, Kirpalani H, Dukhovny D. Should we believe in transfusion-associated enterocolitis? Applying a GRADE to the literature. Semin Perinatol. November 2016. doi:10.1053/j.semperi.2016.09.021.

241. Fisher JG, Jones BA, Gutierrez IM, et al. Mortality associated with laparotomyconfirmed neonatal spontaneous intestinal perforation: a prospective 5-year multicenter analysis. J Pediatr Surg. 2014;49(8):1215-1219.

doi:10.1016/j.jpedsurg.2013.11.051.

242. Ludvigsson JF, Otterblad-Olausson P, Pettersson BU, Ekbom A. The Swedish personal identity number: possibilities and pitfalls in healthcare and medical research. Eur J Epidemiol. 2009;24(11):659-667. doi:10.1007/s10654-009-9350-y.

243. Gordon P, Christensen R, Weitkamp J-H, Maheshwari A. Mapping the New World of Necrotizing Enterocolitis (NEC): Review and Opinion. E-J Neonatol Res. 2012;2(4):145-172.

244. Battersby C, Longford N, Costeloe K, Modi N, UK Neonatal Collaborative Necrotising Enterocolitis Study Group. Development of a Gestational AgeSpecific Case Definition for Neonatal Necrotizing Enterocolitis. JAMA Pediatr. 2017;171(3):256-263. doi:10.1001/jamapediatrics.2016.3633.

245. Epelman M, Daneman A, Navarro OM, et al. Necrotizing enterocolitis: review of state-of-the-art imaging findings with pathologic correlation. Radiographics. 2007;27(2):285-305. doi:10.1148/rg.272055098.

246. Tepas JJ, Sharma R, Leaphart CL, Celso BG, Pieper P, Esquivia-Lee V. Timing of surgical intervention in necrotizing enterocolitis can be determined by trajectory of metabolic derangement. J Pediatr Surg. 2010;45(2):310-313; discussion 313-314. doi:10.1016/j.jpedsurg.2009.10.069. 


\section{Papers}

The papers associated with this thesis have been removed for copyright reasons. For more details about these see:

http:// urn.kb.se/ resolve?urn=urn:nbn:se:liu:diva-142375 